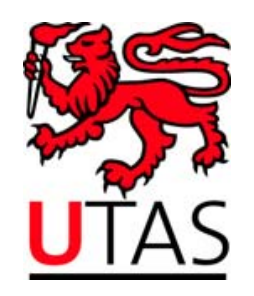

SCHOOL OF ECONOMICS AND FINANCE

Discussion Paper 2012-09

Exchange Rate Risk Exposure and the Value of European Firms

Fabio Parlapiano and Vitali Alexeev

ISSN 1443-8593

ISBN 978-1-86295-682-7 


\title{
Exchange rate risk exposure and the value of European firms ${ }^{\text {th }}$
}

\author{
Fabio Parlapiano ${ }^{\mathrm{a}, *}$, Vitali Alexeev ${ }^{\mathrm{b}}$ \\ ${ }^{a}$ Sapienza University of Rome, Management Department, Rome, Italy \\ ${ }^{b}$ University of Tasmania, School of Economics and Finance, Hobart, Australia
}

\begin{abstract}
We investigate the exposure of European firms to unexpected exchange rate changes of the Euro against currencies of Europe's main trade partners: the USA, UK, and Japan. Using monthly data for the period from 1999 to 2011 and accounting for underlying macroeconomic fundamentals, the analysis covers 600 firms - constituents of the Euro Stoxx TMI and the Euro Stoxx 50. The large number of firms in the sample furthers the insight of how firms' characteristics, that is the level of international involvement, country of origin, industry and firm size associate with the exposure to exchange risks. Among the currency pairs analyzed the Yen is shown to have the highest impact on the market value of European firms, with the largest effect on firms in the financial sector. Moreover, the impact is greater for non exporters and large capitalization firms. The relationship between firms' sensitivities to market and exchange rate fluctuations is explored.
\end{abstract}

Keywords: Exchange rate risk exposure, unexpected exchange rate changes, market and currency beta interdependence, European firms.

JEL codes: - G32, F31, F23, G15.

\section{Introduction}

With the introduction of the single European currency in 1999 the exchange rate risk among Eurozone countries was mitigated, allowing greater price transparency and fostering competition. In addition, the establishment of the single

\footnotetext{
We thank Mardi Dungey, Giovanni Palomba and participants at the 5th International Risk Management Conference for helpful comments and discussion. This work was made possible by the facilities of the University of Cambridge Judge Business School - Center for Financial Analysis \& Policy.

*Corresponding author

Email addresses: Fabio.Parlapiano@uniroma1.it (Fabio Parlapiano), valexeev@utas.edu.au (Vitali Alexeev)
} 
currency area has led to a reduction in market risk exposure of firms with economic activity in Europe (Bartram and Karolyi, 2006) making foreign exchange risk a declining component of common risk factors for European firms. However, the transition from national currencies to the Euro has led to a significant increase in correlations among European equity markets. This form of economic integration has reduced country specific risks, although relevant regional and global effects still remain (Adjaouté and Danthine, 2004). Recent episodes of financial distress experienced by Greece, Portugal and Ireland highlighted the vulnerability of a single currency area. National events such as potential default of a sovereign state, financial crisis or burst of an industry bubble, add to investor's uncertainty and decrease confidence in the single currency, leading to increased risk premiums. These facts increase awareness of the strong ties between the value of the Euro and the value of European equity and bond markets.

This paper analyzes the extent to which the unexpected exchange rate fluctuations affect the market value of European firms. The Euro against currencies of Europe's main trade partners, the USA, UK, and Japan, are considered. ${ }^{1}$ We analyze all constituents of the Euro Stoxx TMI and Euro Stoxx 50 indices, a total of 600 firms, for the period from 1999 to 2011. We classify the firms according to the level of international involvement, country of origin, industry and size. For each subclass of firms we estimate and compare the sensitivity of stock returns to exchange rate fluctuations. Realizing the significant impact of the Global Financial Crisis (GFC) on the Eurozone markets we contrast our findings in two subperiods: the pre-crisis and the crisis period.

The main contributions of this paper are the following: firstly, it fills the gap in the literature on the exposure of European firms to exchange rate risk. Previous studies have addressed the case of the inception of the Euro on the exposure of European and non-European firms to exchange rate risk (Hutson and O'Driscoll, 2010; Muller and Verschoor, 2006a; Nguyen et al., 2007). However, the exclusion of the GFC in the analyzed time period and the sample of firms considered thus far (multinational and non-financial firms), offers only a partial insight of this issue.

Secondly, this paper extends the current evidence by comparing results obtained within two different frameworks: the Augmented Market Model ap-

The European Central Bank (ECB) estimates a synthetic competitiveness measure for the effective exchange rates (EER) as geometrically weighted averages of bilateral exchange rates of the Euro against the currencies of the Eurozone's main trading partners. The weights are based on combined imports and exports of manufactured goods. Based on ECB data for the period from 2007 to 2009, the USD, GBP and JPY by far outweigh other Eurozone trade partner currencies. 
proach (Jorion, 1990) and the Orthogonal Market Model approach (Doukas et al., 2003; Priestley and Ødegaard, 2007). Although the former has received large attention by academics, the critical points of its specification make Jorion (1990) model unsuitable for investigating the interaction between market risk and exchange rate risk. These weaknesses, however, have been addressed in the Orthogonal Market Model.

Thirdly, the results of this study further understanding of the impact of exchange rate fluctuations on firm's value by highlighting how different firm characteristics (e.g., level of international involvement, country of origin, industry, and size) relate with the magnitude of the exposure to exchange rate risks. Considering the Eurozone is the world's second largest currency area, the Euro is an attractive prospect for other trading nations, allowing access to a large market using single currency. The volume of Eurozone exports have increased by $150 \%$ in the period from 1999 to $2011^{2}$, it is therefore not surprising that the impact of exchange rate fluctuations on the value of European firms is of a great concern in corporate risk management, particularly during periods of financial distress recently experienced by Eurozone countries.

The structure of the paper is as follow: Section 2 reviews theoretical and empirical literature on exchange rate exposure. Section 3 details the approach taken in estimating the sensitivities of stock returns to exchange rate fluctuations. Section 4 describes the data and presents descriptive statistics. Our findings are discussed in Section 5. Section 6 concludes.

\section{Previous empirical findings}

Although the literature examining exchange rate exposure of firms is vast, European financial markets have not received as much attention as their US counterparts. The introduction of the single currency in 1999 presented a "natural experiment" to ascertain empirically the economic impact of the elimination of the exchange rate risk among Eurozone countries. Several studies have addressed this issue in an attempt to assess the economic convergence among European countries in the aftermath of the Euro emergence. Only a few studies have investigated the exposure of European firms to fluctuations of the Euro. In comparison, numerous studies have analyzed the impact of the US Dollar exchange rate on US firms.

Since the inception of the Euro, the literature has established several common findings:

- the transition to a single currency have led to an absolute reduction in the number of European non-financial firms significantly exposed to exchange

\footnotetext{
${ }^{2}$ Data on exports of goods and services are obtained from the European Central Bank (ECB).
} 
rate fluctuations. In comparison, non-European firms with similar characteristics have experienced smaller reductions (Bartram and Karolyi, 2006; Koutmos and Knif, 2011);

- the sensitivity of stock returns to currency fluctuations has decreased even after accounting for difference in risk management practices (for the use of operational and financial hedging instruments see Nguyen et al., 2007);

- the reduction in exchange rate risk brought about by the introduction of the Euro is accompanied by a significant decrease in market risk exposure of non-financial firms. The decrease of market risk exposure is greater for firms with foreign business activities in Europe, compared to firms of similar size or operating in the same industry that have no foreign sales or assets in Europe (Hutson and O'Driscoll, 2010; Muller and Verschoor, 2006a; Bartram and Karolyi, 2006).

To the best of our knowledge this literature represents the extent of the analysis of exchange rate risk exposure specific to European firms (a detailed report of methods and findings of each of the studies cited is presented in Table 12). The findings above have been obtained within a commonly used modeling framework, the Augmented Market Model approach based on Jorion (1990) as outlined below:

$$
r_{i t}=\beta_{0}+\beta_{1} r_{s t}+\beta_{2} r_{m t}+\mu_{t} .
$$

Here, the stock return, $r_{i t}$, for a firm $i$ is regressed on the contemporaneous exchange rate return, $r_{s t}$, and the market portfolio return, $r_{m t}$. A firm is identified as being exposed to exchange rate risk when its market value reaction is greater (or less) than the market overall reaction to exchange rate fluctuations. Hence, the coefficient $\beta_{1}$ represents the excess exchange rate exposure, greater (or less) than the market overall reaction to currency fluctuations. The outcomes based on this modeling framework need to be carefully interpreted. When the correlation of stock returns with the returns on the market portfolio is close to 1 , the exposure coefficient $\beta_{1}$ does not capture any significant relationship even though the actual shareholder value is affected by currency fluctuations. In this case the reaction of the firm's value to exchange rate fluctuations is equal to the market portfolio behavior. Furthermore, as we describe in the next three paragraphs, the Augmented Market Model posits some critical points related to the specification of the market risk factor, the exchange rate risk factor and the interactions between the two systematic risk components.

Firstly, the choice of the market index in (1) influences the sign, magnitude and significance of the estimated exchange rate exposure coefficient, $\beta_{1}$. Comparing the results obtained with an equally-weighted, value-weighted and firm size-matched market portfolios, Bodnar and Wong (2003) showed that, when 
large firms are over represented in the index, the estimated exposure coefficients are biased compared to the results based on a broad market index.

Secondly, the exchange rate risk factor should capture all relevant exchange rate movements affecting firm's value. In a rational expectations framework expected exchange rate variations are already priced in the current stock prices, therefore only unexpected currency fluctuations should affect firm's future cash flows, its discount rate and hence firm's market value. This observation requires defining the investor's exchange rate expectation model in order to distinguish the expected and the unexpected components of the exchange rate variations. In this regard, the market rationality hypothesis is extensively supported in the literature. Meese and Rogoff (1983) compared the accuracy of out-of-sample forecasts of various structural and time series exchange rate models and found that the forecasting power of a random walk model performs as well as any of the other existing models at one to twelve month forecast horizon. This evidence corroborated the market rationality hypothesis underlying most of the empirical studies on exchange rate exposure. Assuming the random walk behavior of the exchange rate as the shared investor's expectation model, the unexpected exchange rate movements are empirically operationalized by realized changes in spot exchange rates. There is, however, a lack of consensus regarding the out-of-sample performance of random walk forecasts over any other alternative expectations model. In fact, a certain degree of persistence in exchange rate changes for most currencies has led researchers to consider market's expectation of future exchange rate changes - to a certain extent - as a function of past information. Based on rational expectations, investors might use macroeconomic fundamentals to forecast short term exchange rates movements. The unexpected exchange rate fluctuations are then defined as the residuals from this relationship. ${ }^{3}$ Another related issue has to do with determination of the relevant exchange rate index. In empirical research, trade-weighted exchange rate indices or bilateral exchange rate indices are often employed. While the use of a single currency is usually employed to focus on the firm value impact in the case of one dominant trading partner, it may lead to a partial representation of the firm-specific exposure. Thus, the set of currencies considered should be a function of the firm's specific strategic position (see Jongen et al., 2012). ${ }^{4}$ On the other hand, the trade-weighted indices hide the problem of low and

\footnotetext{
${ }^{3}$ In the recent study, Jongen et al. (2012) defines the unexpected exchange rate as the difference between the realized exchange rate and survey-based expectations on future exchange rate.

${ }^{4}$ Jongen et al. (2012) document an increasing significance of exposure coefficients when the exchange risk factors of the region with which the firms engages in real trading activities are explicitly considered. Analytically, the authors disaggregated the world-wide trade weighted exchange rate index into six region-specific trade-weighted indices using these as risk factors for firms that effectively trade in those regions.
} 
negative correlations among currency pairs over time and, through the diversification effect within the currency portfolio, may lead to an underestimation of corporate exposure (see Miller and Reuer, 1998).

Thirdly, the excess exchange rate risk exposure does not allow disentanglement of the co-movements between market returns and exchange rate returns. In the case where the market risk factor and the exchange rate risk factor interact, estimators controlling for both of these factors may be subject to collinearity. The association between the endogenous variables, the stock market returns and exchange rate returns, might reflect the influence of economic factors or exogenous shocks on both the exchange rate and the stock returns. Thus, equation (1) may simply capture a spurious relation. Suppose, for example, there is a reduction in interest rates that simultaneously stimulates the economy and depreciates the domestic currency. If stock returns rise due to the stimulation from lower interest rates and if, simultaneously, the currency depreciates, then it may appear that there is a direct relationship between stock returns and exchange rates when in fact there is none (Priestley and Ødegaard, 2007). Therefore, measures of market risk and exchange rate risk exposures cast doubt on their interpretation when common factors affect both. Given that market and exchange risk factors might be correlated or jointly influenced by common external shocks, several studies have developed modeling adjustments to preserve the consistency of linear regression estimates. These developments rely on two main approaches to handle the collinearity problem. The first approach is to orthogonalize the risk factors in order to obtain uncorrelated components (see Choi and Prasad, 1995; He et al., 1996; Kiymaz, 2003), while the second approach explicitly adds explanatory variables to proxy the economic factors that are supposed to drive both the market returns and the exchange rate fluctuations (see Miller and Reuer (1998); Gao (2000); Chen et al. (1986)). The Orthogonal Market Model employed by Doukas et al. (2003) and Priestley and Ødegaard (2007) merge both of these approaches by identifying common economic factors and by orthogonalizing market and currency risk factors.

To address the issue of exchange rate risk exposure of European firms, this study analyzes a large sample of firms across several industries and among 15 Eurozone members during the period from 1999 to 2011. Specifically the following questions are addressed:

1. How unexpected exchange rate fluctuations affect firm's market value within the European context and whether these effects strengthen during the period of Financial Depression?

2. Are multinational firms more exposed to exchange rate risk than domestic firms?

3. Are financial firms (particularly in countries recently affected by sovereign financial distress) more exposed to exchange rate fluctuations than nonfinancial firms? 
4. After decomposing the market and exchange rate risks, to what extent stocks that are insensitive to market fluctuations (market defensive stocks) provide a hedge against fluctuations in exchange rate?

\section{Modeling framework}

We estimate the exposure of European firms to unexpected exchange rate fluctuations within two modeling frameworks: the Augmented Market Model approach in Jorion (1990), and the Orthogonal Market Model approach as introduced in Doukas et al. (2003) and later in Priestley and Ødegaard (2007). The former estimates the excess exposure coefficients, and is comparable with the evidence presented in earlier studies (e.g. Muller and Verschoor (2006b); Bartram and Karolyi (2006); Nguyen et al. (2007); Hutson and O'Driscoll (2010); Inci and Lee (2011)). The latter takes into account the joint influence of common economic factors on both the market and exchange rate returns. Decomposing the market and exchange rate risks allows to explore how sensitive stock returns are to fluctuations in exchange rate (currency defensive) separate from market influence (market defensive). Thus, the exposure coefficient captures only the sensitivity of stock returns to exchange rate fluctuations which are orthogonal to stock market returns. To this date, this approach has only been applied to the Japanese (Doukas et al., 2003) and the US (Priestley and Ødegaard, 2007) financial markets. This research contributes to the literature by providing new comparative evidence for the Eurozone financial market.

The Augmented Market Model, briefly introduced in previous section in equation (1), is used for direct comparison with the earlier studies. Instead, in this paper we focus and draw our conclusions based on the Orthogonal Market Model. Within the Orthogonal Market Model approach, the evolution of currency and stock market behavior is expressed as a function of a set of macroeconomic fundamentals. In particular, investors' expectations about the exchange rate and stock market movements at time $(t+1)$ are based on the information that is available to them at the beginning of each period $(t)$. The unexpected exchange rate variations related to the firm's currency exposure, and the unexpected stock market variations are obtained with a three-stage estimation procedure. Analytically, the first stage requires the identification of the unexpected exchange rate return, $\varepsilon_{s t}$. This is obtained by regressing the exchange rate changes, $r_{s t}$, on the first lag of the dependent variable, $r_{s t-1}$, and

a set of control variables, $C V_{j, t-1}$, observed at the beginning of each period as follow:

$$
r_{s t}=\beta_{0}+\sum_{j=1}^{6} \beta_{j} C V_{j, t-1}+\beta_{7} r_{s t-1}+\varepsilon_{s t},
$$

where $C V_{j, t-1}$ are lagged control variables as detailed in Table 1 .

Equation (2) relies on the standard random walk behavior of the exchange 
rate and the additional information provided by a set of economic factors. The control variables are chosen according to Chen et al. (1986) who have shown that these state variables have systematic influence on stock market returns. The unexpected exchange rate changes can then be defined as:

$$
\widehat{\varepsilon_{s t}} \equiv r_{s t}-\widehat{\beta}_{0}-\sum_{j=1}^{6} \widehat{\beta}_{j} C V_{j, t-1}-\widehat{\beta}_{7} r_{s t-1}
$$

In the second stage we obtain the estimated unexpected market portfolio return, $\widehat{e_{m t}^{M}}$, by regressing the market portfolio return, $r_{m t}^{M}$, on the set of lagged control variables as before, the first lag of the dependent variable, $r_{m t-1}^{M}$, and the estimated residual from (3) above:

$$
r_{m t}^{M}=\beta_{0}+\sum_{j=1}^{6} \beta_{j} C V_{j, t-1}+\beta_{7} r_{m t-1}^{M}+\beta_{8} \widehat{\varepsilon_{s t}}+e_{m t}^{M} .
$$

The unexpected stock market portfolio return can than be definite as:

$$
\widehat{e_{m t}^{M}} \equiv r_{m t}^{M}-\widehat{\beta}_{0}-\sum_{j=1}^{6} \widehat{\beta}_{j} C V_{j, t-1}-\widehat{\beta}_{7} r_{m t-1}^{M}-\widehat{\beta}_{8} \widehat{\varepsilon}_{s t-1} .
$$

Here, $M$ denote a specific market index, in our case $M$ is either the Euro Stoxx TMI or the Euro Stoxx 50. By construction, the estimated unexpected exchange rate, $\widehat{\varepsilon_{s t}}$, and the unexpected market portfolio return, $\widehat{e_{m t}^{M}}$, are orthogonal following the inclusion of the $\widehat{\varepsilon_{s t}}$ component in (4). He et al. (1996) applied the same procedure to attenuate the collinearity problem. However, the unexpected component of the exchange rate movement does not necessary evolve exogenously, some unobservable nominal or real aggregate shocks may affect both the stock market return and the exchange rate. Hence, the endogeneity of the exchange rate may still result in a bias and inconsistency in the exposure estimation model (Gao, 2000).

The first and second stage specifications proposed here differ from the Doukas et al. (2003) model, to the extent that we do not include the FamaFrench factors (Fama and French, 1992, 1993), namely size and value, as explanatory variables. Several studies document the extent of the size and value effect in the financial markets around the world, and while all of them were able to identify a return premium, the measure of the premiums vary across different financial markets. Dimson et al. (2002) document country specific differences among the European countries both for size and growth premiums ${ }^{5}$,

\footnotetext{
${ }^{5}$ Dimson et al. (2002) review previously estimated results on the size and value effect in equity markets around the world. These have led us to consider the variability of risk premiums within the European countries, and specifically, the results for the size effect. The
} 
hence a unique measure for those factors can not be applied at the Eurozone level.

The final third stage involves estimating the sensitivity of stock returns to the unexpected exchange rate and unexpected stock market portfolio returns. We express this relationship below:

$$
r_{i t}=\alpha_{0}+\sum_{j=1}^{6} \beta_{j} C V_{j, t-1}+\beta_{i 7} r_{i t-1}+\beta_{i m} \widehat{e_{m t}^{M}}+\beta_{i s} \widehat{\varepsilon_{s t}}+\gamma_{i t} .
$$

The model specification in (6) takes into account the set of economic factors, and the first lag of the dependent variable, $r_{i t-1}$. The endogeneity problem arising from common (observable) underlying factors that drive the exchange rate and the stock market returns is attenuated in (6) since $\widehat{\varepsilon_{s t}}$ and $\widehat{e_{m t}^{M}}$ are, by construction, orthogonal to each other and the set of economic variables included in (2) and (4).

\section{The data}

Focusing on the firms operating in the Eurozone, we consider all constituents of a broad market index, the Euro Stoxx TMI (600 firms), and constituents of a large capitalization index, the Euro Stoxx 50 (50 firms). Both indices have a diverse coverage of the Eurozone countries ${ }^{6}$, with an economic performance benchmark of the Eurozone in the former, and a large capitalization focus and value weighted selection criteria in the latter. ${ }^{7}$ The large number of firms in the sample allows for a breakdown based on geographical location, industry, level of international involvement, and the size of the company. Monthly data used in this study are obtained from Bloomberg, and Stoxx Ltd.

The broad coverage of the Euro Stoxx TMI index, enables us to estimate the exchange rate exposure coefficient without a size bias that may arise due to over representation of large firms in the market proxy as would be the case with the Euro Stoxx 50 index. $^{8}$ In terms of a number of securities, the industry and

size premiums are: $0.49 \%$ for Belgium, $0.76 \%$ for Finland, $0.90 \%$ for France, and $0.56 \%$ for Spain. The value premium results are: $0.29 \%$ for Belgium, $0.52 \%$ for France, $0.26 \%$ for Germany, $-0.24 \%$ for Italy, and $0.10 \%$ for the Netherlands.

${ }^{6}$ The indices cover 12 Eurozone countries: Austria, Belgium, Finland, France, Germany, Greece, Ireland, Italy, Luxembourg, the Netherlands, Portugal and Spain.

${ }^{7}$ The number of constituents of the Euro Stoxx TMI varies to coverage of approximately $95 \%$ of the free float market capitalization of the European Monetary Union, while the Euro Stoxx 50 covers $60 \%$ of the free float market capitalization of the TMI super sector index.

${ }^{8}$ The over representation of large firms affects both the market risk premium and the exchange rate risk exposure coefficients. In regards to the market risk premium, ? point out that when an index is designed to cover only the largest stocks in the market, a success bias 
geographical segmentations are similar for both indices: the industrial sector is represented by almost $85 \%$ of the constituents; France, Germany and Italy combined account for more than $60 \%$ of the constituents.

By considering the non-Eurozone revenues to total revenues ratio we account for the firm's level of involvement in international operations or, more precisely, non-Eurozone operations. ${ }^{9}$ The statistic on non-Eurozone revenues to total revenues ratio, hereafter the Foreign Exchange Exposure (FEE) index ${ }^{10}$, is presented in Table 2. The average degree of international involvement in period from 2005 to 2010 is higher for Euro Stoxx 50 constituents (at 46.00\%) than for Euro Stoxx TMI (at 39.52\%). This shows that, on average, large European firms make approximately half of their revenues outside the Eurozone countries. The FEE index for Euro Stoxx 50 constituents is more homogeneous (sample standard deviation 23.25\%) than for Euro Stoxx TMI constituents (sample standard deviation $31.06 \%$ ). This is not surprising given wide industry coverage that characterize the TMI index. Using the time standard deviation to represent the sample average variability of the FEE index during the 5-year period, we observe that the level of international involvement is stable throughout the period for both indices (time standard deviation of $4.58 \%$ and $4.89 \%$ for Euro Stoxx 50 and Euro Stoxx TMI respectively). Therefore, it is reasonable to assume that the exchange rate risk exposure, specifically the transactional exposure $^{11}$, is constant.

We group the firms by their degree of international involvement on the basis of the FEE index threshold as in Doukas et al. (2003). We consider high

occurs as an over representation of companies that grew large enough to enter the index. Concerning the exchange rate exposure, Bodnar and Wong (2003) observe that, when large firms are over-represented in the market index, a common characteristic of a value-weighted market indices, a positive bias in the exposure coefficients occurs, due to the fact that these firms are likely to be more export oriented.

${ }^{9}$ The degree of international involvement can be accounted for by several indicators: for example i) the foreign sales to total sales ratio, ii) the foreign assets to total assets ratio, iii) the foreign tax to total tax ratio (as long as the country where income tax are paid is the same country where income is produced), and iv) the foreign income to total income ratio. All these indicators have been gauged for the indices constituents but, insufficient geographic segmentation data disclosed by companies prevented us from constructing comprehensive and consistent data set. For this reason the non-Eurozone revenues ratio is the only indicator used in our analysis.

${ }^{10}$ The geographic segmentation of revenues from 2005 to 2010 is provided by Bloomberg for companies that disclose this information in their balance sheet notes. Since not all of the sampled firms disclose the revenues segmentation, only the ones with available data were included during estimation of exposure coefficients when the international involvement criterion was considered. Interestingly, all of these firms are part of the banking and financial industry, leading us to believe that their hedging structure may explain the difference in sensitivities to to exchange rate fluctuations.

${ }^{11}$ The exchange rate transaction exposure occur when exchange rate fluctuations happen during the lead time to settle an asset (credit) or a liability (debt). 
exporters (or MNCs), low exporters, and non-exporters (or domestic firms). The summary results for these subgroups are reported in Table 2. Reasonably, no domestic firms are found among the constituents of the Euro Stoxx 50. Some similarities, however, can be observed in the high and low exporter groups: the average international involvement is around $50 \%$ for high exporters and $10 \%$ for the low exporters. Also, low exporters show a more concentrated distribution within the subgroup (sample standard deviation of $5.86 \%$ and $6.23 \%$ for Euro Stoxx 50 and Euro Stoxx TMI), while high exporters are more diverse (sample standard deviation of $20.22 \%$ and $24.30 \%$ for Euro Stoxx 50 and Euro Stoxx TMI respectively).

The breakdown of Euro Stoxx TMI constituents by industry when grouped as domestic, low exporters and MNCs is represented in Figure 1. The highest concentration of MNCs (high exporters) is in the industrial sector $(73.06 \%$ ) followed by the Utility $(50.00 \%)$ and the Real Estate (37.50\%). On the other side of the spectrum, the proportion of domestic firms is highly concentrated in non-industrials, that is Financials, Banking, and Insurance sectors.

Monthly data for the set of economic variables and nominal bilateral exchange rates are obtained from the ECB Statistical Data Warehouse. In accordance with Chen et al. (1986) and Doukas et al. (2003) we rely on six control variables to express the macroeconomic factors of interest: unexpected inflation, $U I$, industrial production, $I P$, term premium, $T P$, money supply, $M S$, interest rate spread, $I R S$, and trade balance, $T M$. Detailed list of these variables is presented in Table 1 . With the exception of the $U I$, all of the control variables are selected and computed following Chen et al. (1986) and Doukas et al. (2003) specifications. We performed Fama and Gibbons (1984) procedure in order to obtain expected and unexpected inflation. However, due to low volatility of inflation within the Eurozone, the above procedure was not consistent with its statistical assumptions. Instead, we compared the results from different unexpected inflation proxy selecting the realized previous month rate of inflation. ${ }^{12}$

\footnotetext{
${ }^{12}$ Unanticipated inflation is the difference between realized monthly inflation rate in period $(t)$ and the expected inflation rate in period $(t)$, conditioned on the information available at the end of period $(t-1)$. We performed the (Fama and Gibbons, 1984) procedure to extract market inflation expectations from the Fisher's interest rate relationship. The actual behavior of the inflation rate within the Euro area exhibit features that violates the inflation expectations model of Fama and Gibbons (1984), that is the hypothesized random walk behavior of expected real rate of return. The comparative assessment of three proxies for the expected inflation: i) the world oil price index variations (as approximated by the West Texas Intermediate); ii) the European Central Bank survey of professional forecasts; and iii) the previous month realized inflation respectively, led us to the use of the latest. Accordingly, Gao (2000) employs the realized inflation rate as a control variable to identify unexpected exchange rates variations.
} 


\section{Results}

We focus on the exchange rate exposures of European firms obtained through the Orthogonal Market Model approach (Doukas et al., 2003; Priestley and Ødegaard, 2007). We contrast our findings with the results based on the Augmented Market Model approach (Jorion, 1990), the mainstream empirical model widely employed in previous studies. Further, we explore the interdependence between exposure to market risk and exposure to currency risk with a use of the quantile regression model of Koenker and Hallock (2001).

\subsection{Model estimation}

We first turn our attention to Table 3 detailing the first stage estimation in (2) for all three pairs of currencies where investors expectations of the exchange rate changes are based on identified previous month macroeconomic fundamentals. The currency pairs analyzed are only weakly influenced by the set of macroeconomic fundamentals. At this stage, the first lag of the exchange rate return and the Euro's money supply are the only significant determinants of exchange rate changes with no significant effect for the remaining factors. While the joint hypothesis of null coefficients is rejected for the JPY/EUR and $\mathrm{USD} / \mathrm{EUR}$, the GBP/EUR is found to be independent of all macroeconomic variables ( $F$-statistic, Table 3$)$. These findings are consistent with previous studies on exchange rate forecasting, where the random walk path of exchange rates is still the benchmark model for the short run behavior of exchange rates (Meese and Rogoff, 1983). The first stage does not attempt to forecasts the exchange rate itself, instead it is aimed to identify the unexpected exchange rate return, $\widehat{\varepsilon_{s t}}$. We report the Jarque and Bera (1987) (JB) test statistic in Table 3 , formally providing a support to the existence of an informative structure in the unexpected exchange rate returns.

Investors' expectation of market portfolio returns are based on identified previous month macroeconomic fundamentals while taking into account the impact of unexpected exchange rate changes on the stock market value. Using (4) in the second stage, we estimate the unexpected market portfolio returns and present the results in Table 4 for both market return proxies: the Euro Stoxx TMI and Euro Stoxx 50. Although the hypothesis of joint null coefficients is rejected, the Eurozone stock market is only weakly influenced by the set of macroeconomic fundamentals. We tested the significance of only macroeconomic variables in a restricted model in (4). Contrary to first stage estimation, the macroeconomic variables were found to be statistically different from zero, confirming the weak but significant influence of identified factors when considered jointly. In particular, we find that realized inflation is negatively related with stock market returns providing corroborating evidence of 
the inflation puzzle as in the earlier work of Fama (1981). ${ }^{13}$ Unexpected exchange rate fluctuations in the JPY/EUR have significant and positive impact on both market indices. These findings are consistent with Doukas et al. (2003), who document the weak significance of macroeconomic variables as proxies for the underlying risk factors driving stocks returns of Japanese financial market. These results, however, differ from the reference study of Chen et al. (1986) and Hamao (1988), who document the pricing relevance of the macroeconomic state variables for the US and Japan markets. The JB test results in Table 4 provide additional support to the existence of an informative structure in market return residuals, $\widehat{e_{m t}^{M}}$.

With the currency and market risk factors now satisfying the orthogonality condition, we turn to our final, third stage as detailed in (6). The sensitivity of stock returns to unexpected exchange rate variations is captured by the coefficient $\beta_{i s}$ and is of primary interest in this paper. We perform estimations for the full sample period, 1999 - 2011, and for two sub periods: March 1999 June 2007 (pre-crisis period) and July 2007 - September 2011 (crisis period). ${ }^{14}$ Securities with less than 5 years of data were excluded from the analysis, resulting in 529 firms for the Stoxx TMI and 49 firms for the Stoxx 50. Tables 5 and 6 summarize ordinary least squares (OLS) heteroskedasticity robust estimates of the exchange rate exposure in (6) for the Euro Stoxx TMI and the Euro Stoxx 50 constituents respectively. We report the percentage of firms significantly affected by exchange rate fluctuations, the average magnitude of significant exposure coefficients and the number of firms positively, $N^{+}$, and negatively, $N^{-}$, affected by currency variations.

Considering the full sample period we find that the percentage of firms significantly affected by the JPY/EUR exchange rate fluctuation is the largest among the three currency pairs considered, representing $27.60 \%$ of the Euro Stoxx TMI constituents. During this period, the appreciation of the Euro against JPY is associated, on average, with an $8.2 \%$ increase in stock returns for each $10 \%$ change in exchange rate. Although the impact of appreciating Euro against the USD and GBP is positive and similar to that of the JPY

\footnotetext{
${ }^{13}$ Fama (1981) argues that stock returns are determined by forecasts of real variables. Negative relations between stock return and inflation, both expected and unexpected components, are induced by negative relations between inflation and real activity. Consistent with the results obtained for the US data, Gultekin (1983) extended the analysis to 26 countries and found evidence of negative relation between stock returns and inflation. In contrast, Boudoukh and Richardson (1993) found evidence that long horizon (1 year and 5 years) nominal stock returns are positively related to both ex ante and ex post long term inflation.

${ }^{14}$ The ECB time-line of the GFC reports a state of increasing market vulnerability on the 15th of June 2007. The state of worldwide liquidity shortage, identifying the beginning of the sub-prime crisis, is conventionally reported on August 2007. Accordingly, the start of the crisis has been dated as July 2007 in Dungey et al., 2009; Fry et al., 2010, 2011.
} 
(6.8\% and $7 \%$ respectively), the proportion of firms with significant impact is considerably smaller ( $13.04 \%$ and $10.78 \%$ of constituents respectively). This result is consistent with the study of Muller and Verschoor (2006b) on European MNCs in that the value of European firms increases in response to appreciation of the Euro. Operationally, this situation would be consistent with a scenario where European firms are net importers from these countries, however, this is not the case. Except for the Japan, the Eurozone trade balance against the UK and the US have recorded surplus positions in the period analyzed. We argue that net export positions of the firms are not the key determinants of their exposure to the exchange rate risks. Most likely, given that actual net export positions have already been priced in the value of Euro, they are not part of unexpected exchange rate fluctuations. ${ }^{15}$

The percentage of firms exposed to exchange rate fluctuations is higher for the Euro Stoxx 50 constituents (in Table 6: 42.86\% for JPY, 26.53\% for USD, and $20.41 \%$ for GBP) than for the Euro Stoxx TMI constituents (in Table 5: $27.60 \%$ for JPY, $13.04 \%$ for USD, and $10.78 \%$ for GBP). This is not surprising given the fact that the Euro Stoxx 50 is comprised of the largest MNCs in Eurozone (37 out of 43 firms are identified as high exporters, see Table 2 on page 25). Having said that, the magnitude of the exposure coefficients, $\beta_{i s}$, can not be compared between indices in absolute terms since it depends on the particular market index analyzed. Keeping this in mind, one can argue based on results in Table 6 that the GBP has the highest impact with $9.5 \%$ stock return sensitivity for each 10\% exchange rate variation, followed by the JPY $(6.7 \%)$ and the USD (5.9\%). This result, however, is not indicative of the Eurozone stock market overall (when the Euro Stoxx TMI index is employed) and may be related to different trade relationships or risk management practices of large capitalization firms.

We contrast the results discussed above with those of the two subperiods: i) from March 1999 to June 2007 and ii) from July 2007 to September 2011. In Tables 5 and Table 6 we estimate currency trends indicative of the variations in the Euro against the USD, GBP and JPY for the full period as well as the two subperiods. ${ }^{16}$ The first subperiod is characterized by appreciation of the Euro against the JPY $(+24.83 \%)$ and the USD $(+23.04 \%)$, while remaining relatively stable against the GBP $(+0.56 \%)$. During the second subperiod, the Euro depreciated substantially against the JPY (-29.54\%), while maintaining a relatively stable exchange rate with the USD $(+6.31 \%)$ and, on the contrary, experienced an appreciation against the GBP $(+30.12 \%)$. Considering the Euro Stoxx TMI index, the value of European firms is positively affected

\footnotetext{
${ }^{15}$ Source: Eurostat, Extra-euro area (EA17) trade, by main partners, total product.

${ }^{16}$ The rate of change is computed as $\frac{P_{t}}{P_{t-n}}-1$, where $P_{t}$ is the exchange rate. In order to mitigate short term fluctuations in the exchange rate we compute the six months moving average of the exchange rate.
} 
by fluctuations of all the currencies analyzed, independently of whether the Euro appreciates or depreciates (note, however, that these results are in direct contrast with those obtained using the Orthogonal Market Model approach detailed in Tables 7-8 when the orthogonality issue of the two systematic risk components is not addressed). Meanwhile, we find that the number of firms significantly affected by these fluctuations have more than doubled during the second subperiod compared to the first. The magnitude of exposure coefficients, on average, has increased during the second subperiod with the only exception of the GBP. Furthermore, it is interesting to note that despite the variability in the number of firms significantly affected during the full period, the proportion of positive and negative exposure coefficients is almost constant between subperiods for the USD and JPY. These results hold, to a lesser extent, for the Euro Stoxx 50 constituents. Overall, our findings support the conjecture of a different impact of exchange rate fluctuation during the pre-crisis and the crisis subperiods. In particular, this study highlights the time varying nature of exchange rate sensitivity of stock returns and its increased exposure during the crisis period.

It is interesting to contrast the results obtained trough the Augmented Market Model approach with those of Orthogonal Market Model. The Orthogonal Market Model was the mainstream approach in the literature. It was first introduced by Jorion (1990) and was applied in Muller and Verschoor (2006b), Bartram and Karolyi (2006), Nguyen et al. (2007), Hutson and O'Driscoll (2010) and Inci and Lee (2011). By comparing the two approaches, we do not attempt to reconcile the estimations obtained within these two different modeling frameworks. Instead, we attempt to provide evidence of the measurement bias, if any, when estimations of the exchange rate exposure are obtained using Jorion (1990) approach. We have previously argued in Section 1, that the collinearity between risk factors and the improper use of realized exchange rate changes as proxy of unexpected changes, may contribute to the bias. Tables 7 and 8 report the heteroskedasticity robust OLS estimates of the exchange rate exposure coefficients in (1) for both indices.

The percentage of firms significantly affected by realized exchange rate fluctuations is smaller than the proportion measured within the Orthogonal Market Model approach. As an example, for the JPY the measurement bias is $42.46 \%$ for the Euro Stoxx TMI constituents and $61.90 \%$ for the Euro Stoxx 50 constituents. The reason for such large departure is that the exposure coefficients in Jorion (1990) model capture only the stock return sensitivity to exchange rate fluctuations in excess to the market portfolio overall sensitivity. Therefore, a systematic underestimation of the proportion of firms significantly affected is due to this modeling framework configuration of exposure coefficients and, in fact, may partially justify the exchange rate exposure puzzle. Large capitalization firms are more exposed than the Eurozone stock market overall (as proxied by the Euro Stoxx TMI constituents), a finding which is consistent with previ- 
ous results in Table 6 . Looking at the average magnitude of significant exposure coefficients, the Augmented Market Model again underestimates the sensitivity of stock returns to exchange rate fluctuations. However, the signs of coefficients are consistent with the results in Tables 5 and 6 with the exception of the GBP for the Euro Stoxx TMI firms. Overall, by identifying and filtering the joint influence of macroeconomic fundamental on the exchange rate, the market and the stock returns, the Orthogonal Market Model approach appears to offer a better picture of the impact of unexpected exchange rate fluctuation on market values of European firms. These results attenuate the extensive evidence of the exchange rate exposure puzzle by increasing the percentage threshold of firms significantly affected and the magnitude of the exposure coefficients previously found in other studies (for the summary of these empirical findings see Table 12).

The firm's level of international involvement is a recognized determinant of firm's exchange rate risk exposure. However, its contribution to the sign, significance and magnitude of the exposure coefficients is ambiguous. Based on findings in previous studies, we do not expect an a priori relationship between the ratio of non-Eurozone revenues to total revenues and the firm's exchange rate exposure. Choi and Jiang (2009) found evidence that the multinationality matters for a firm's exchange exposure but not in the way usually presumed the exchange risk exposures are actually smaller and less significant for MNCs than for non-multinationals. The authors provide evidence that operational hedging decreases firm's exchange risk exposure and increases its stock returns. According to Davies et al. (2006), there is strong evidence indicating that firms with higher proportion of international sales are more likely to hedge foreign exchange exposure. Nevertheless, it is plausible that the effectiveness of these financial and operational hedging may be incomplete when future cash flows are considered. While hedging strategies effectively mitigate current exposure in the short run (i.e, the transaction exposure), the effectiveness of these hedging practices is weak in the long run (i.e, the economic exposure ${ }^{17}$ ). Table 9 reports the exposure coefficients grouped by level of international involvement as approximated by the FEE index in section 4 on page 10 .

From this perspective a clear pattern emerges: the combined proportion of low exporters and domestic firms significantly exposed to exchange rate fluctuations and the average magnitude of significant coefficients is higher than for MNCs, reconfirming the findings in Davies et al. (2006) and Choi and Jiang (2009). This result weakens theoretical doctrine by which, the greater the

\footnotetext{
${ }^{17}$ The economic (or competitive) currency risk exposure reflects changes in expected cash flows related to unexpected change in exchange rates. Economic exposure involves effects of exchange rate changes on all aspects of corporate management: operational, financial, market strategies and, especially, competitors' reactions. As a result, long - term profits and competitive position of the firm may be affected.
} 
firm's level of international involvement, the greater the impact of currency fluctuations on firm's market value. In contrast, our results highlight the relevance of the exchange rate exposure of firms which do not report operations in foreign currencies and the need for a better control of this risk. In fact, risk management policies ${ }^{18}$, may explain the superior performances of MNCs when compared with low exporters in terms of exchange rate exposure. It is interesting to note, however, that when controlling for the level of international involvement, large capitalization firms are more likely to be exposed to exchange rate risk. As an example, $43 \%$ of Euro Stoxx 50 MNCs are significantly affected by exchange rate fluctuations compared with 27\% of Euro Stoxx TMI MNCs (see Table 9 on page 33).

Most of the studies reviewed focused on industrial firms, assuming that the exposure of financial firms may be driven by different aims and factors; particularly the possibility of taking advantage of better forecasts of future exchange rates by financial institutions. Instead, we include financial firms in our analysis. Estimates in Table 10 confirm that firms within the financial industry experienced a much larger positive impact of exchange rate fluctuations than firms outside the financial industry. The proportion of financial firms significantly affected is more than double the proportion of non-financial firms and, in addition, the magnitude of exposure coefficients are greater on average.

Our estimations of exposure coefficients is further explored considering the country of origin. Table 11 shows the country specific breakdown of estimated exposure coefficients. Each country is ranked by the number of firms significantly exposed to currency changes. At the Eurozone level, it is interesting to note that firms in Portugal, Greece and Italy present the highest sensitivity to exchange rate fluctuations for the currencies considered. At the other end of the spectrum firms in Austria, Ireland and Finland experienced the least wealth variations related to fluctuations in the Euro. These differences might be attributed to a relatively large concentration of financial firms for the first group of countries and the linkages of those firms' assets with sovereign debt securities.

18

The IAS 39 (Financial Instrument: Recognition and Measurement) introduced the hedge accounting rule within the international accounting reporting system. The hedging transactions undertaken for the economic aim of reducing potential loss from fluctuations in foreign exchange rates are reported under the IAS 39 if the hedge relationship is effective. Due to the lack of data for the number of European firms that report the value of derivative instruments employed to hedge against exchange rate exposure, we are unable to control for different currency risk management practices. 
5.2. Relationship between sensitivities to market and exchange rate fluctuations

Within the orthogonal market model the exchange rate exposure coefficient captures only the overall sensitivity of stock returns to unexpected exchange rate fluctuations. By construction, the impact of unexpected exchange rate changes on the stock market returns is controlled and filtered. Therefore, the market beta reflects only the sensitivity of stock returns to the market risk factor. Decomposing the market and exchange rate risks allows us to explore how sensitive stock returns are to fluctuations in exchange rate separate from market influence. This, in turn, allows us to measure the extent to which market defensive stocks provide a hedge against exchange rate risk. We investigate the interdependence between estimated currency betas, $\widehat{\beta}_{s}$, and market betas, $\widehat{\beta_{m}^{M}}$, using a quantile regression model, where the exposure to market risk, as captured by the market beta, is the response variable as follows:

$$
\widehat{\beta_{i m}^{M}}=\theta_{0}+\theta_{1}\left(\widehat{\beta_{i s}}\right)+\mu_{i}
$$

where, $\widehat{\beta_{i m}^{M}}$, is the market risk exposure for a firm $i$ estimated from Equation (6) and, $\widehat{\beta_{i s}}$, is the exchange rate risk exposure from Equation (6). We attempt to characterize quantiles, $\tau$, of the conditional distribution of market betas as a function of currency betas. Figure 2 plots OLS quantile regression estimated for $\tau$ ranging from 0.05 to 0.95 (the solid dotted curve). For each of the plots the horizontal axis is the quantile scale and the vertical axis as the response variable scale. In particular, each point measure the impact of a one-unit change of the currency beta on the market beta, holding other covariate fixed. The two solid curves represent $95 \%$ confidence intervals of the estimated coefficients using quantile regression. The dashed line in each plot shows OLS estimate of the conditional mean effect and the two dashed dotted lines represent conventional 95\% confidence intervals for the least squares estimates (details of quantile regression estimations are reported in Table 13).

Our estimation show a positive non-linear relation between exposure coefficients to market risk and currency risk. In particular, the strength of the relationship is greater for the JPY where firms highly exposed to currency risk (the $95^{\text {th }}$ percentile of currency beta distribution) experienced a greater market risk exposure of 0.20 (in market beta scale) when compared with firms less exposed to the JPY (the $5^{\text {th }}$ percentile of currency beta distribution). Therefore, in case of JPY, firms most exposed to exchange rate risk are more likely to experience a greater exposure to Eurozone market risk factor. However, when the GBP and the USD are considered, the interdependence between currency risk and market risk appear less relevant. In particular, firms which occupy the median quantile of currency beta distribution are more likely to be exposed to market risk compared to firms which occupy the last quantile of the distribution. Further, the magnitude of the coefficients for the GBP and USD is less evident than the one for the JPY. 
These estimations, deepen our understanding of the impact of exchange rate fluctuations on market risk exposure and, ultimately, on the firm's value. However, some critical points are in need of attention: i) unobservable macroeconomic fundamentals may still jointly affect the exchange rate and the stock market value, posing a collinearity problem; ii) since the quantile regression is performed on estimated currency and market betas the estimation errors in these variables may adversely impact the assessment of the relationship between currency exposure and market exposure.

\section{Concluding remarks}

Previous works on firms' exchange rate exposure have focused on the US markets and found that the US Dollar exchange rate fluctuations have weak effect on US stock returns. In light of the vast empirical evidence, Bartram and Bodnar (2007) gave rise to the so called exchange rate exposure puzzle. The authors argue that the proportion of firms significantly exposed is not as high as literature leads us to believe. This could be partially attributed to failure to recognize reducing exchange rate exposure. If firms react rationally to the exposure by undertaking operational and financial hedging actions, it is plausible that most firms are not exposed. Alternatively, stock returns reflect only the residual exposure of firms, that is, net of corporate hedging policies. The international evidence on currency exposure provided so far has found significant results for just 10-25\% of the cases (Bartram and Bodnar, 2007).

This study takes into account the joint influence of macroeconomic fundamentals on stock market and exchange rate returns by employing the Orthogonal Market Model approach proposed in Doukas et al. (2003) and later in Priestley and Ødegaard (2007). The results are compared with the mainstream Augmented Market model of Jorion (1990) allowing us to contrast the systematic underestimation of the proportion of firms significantly affected by the exchange rate fluctuations for the latter. We examine the exchange rate exposure of the European firms after the inception of the European common currency, focusing on the three major trading partners of the Eurozone by analyzing the impact of the US Dollar, British Pound and Japanese Yen on the value of European firm. We find that $11 \%$ to $28 \%$ of the Euro Stoxx TMI constituents are significantly affected by exchange rate fluctuations. When compared to the results of other studies on the exchange rate exposure of the European firms, our estimates exceed previous findings (Bartram and Karolyi, 2006; Hutson and O'Driscoll, 2010; Inci and Lee, 2011; Nguyen et al., 2007; Muller and Verschoor, 2006b). We also observe that among the currency pairs analyzed the Yen had the highest impact on the returns of the European firms, with the greatest impact on the firms in the financial sector and for the large capitalization firms. 
We find that stock returns react positively to the Euro appreciation during the 1999-2011 as well as in two subperiods analyzed (1999-2007 pre-crisis period and 2007-2011 crisis period). Interestingly, the percentage of firms significantly exposed increased substantially during the period affected by the Global Financial Crisis. These results provide additional support to the time varying dynamic of exchange rate exposure, despite the potential stability of firms trading relationships.

Contrary to the theoretical conception and previous research findings, our results for low-exporter and domestic subgroups indicate that the level of internationalization, as measured by non-Eurozone revenues on total revenues, does not characterize an a priori exchange rate exposure behavior. Domestic firms appear more exposed than MNCs, highlighting the need for a better corporate management of exchange rate risk by these firms. As expected, firms operating in the financial sectors systematically experience greater exposure to exchange fluctuations both in terms of magnitude and percentage of firms significantly exposed. The country breakdown of the firms reveals different impact of exchange rate fluctuations on these Eurozone national stock markets. In countries that experienced sovereign debt crisis and countries where the concentration of financial firms is larger we observe greater exchange risk exposure.

We investigate the link between the currency and the market risk exposure and find a positive non-linear relationship between estimated currency betas and market betas. In particular, the firms most exposed to currency risk factor are the ones experiencing greater market exposure. We find that this relationship is strongest for the case of the JPY. As a consequence, market defensive stocks may prove to be a good hedging tool against exchange rate risk exposure.

Our results suggest that domestic firms are more vulnerable to unexpected exchange rate fluctuations that MNCs. Further research could examine this interesting finding in a different light by controlling for differences in risk management policies of firms.

\section{References}

Adjaouté, K., Danthine, J., 2004. Equity returns and integration: is Europe changing? Oxford Review of Economic Policy 20 (4), 555-570.

Bartram, S. M., Bodnar, G. M., 2007. The exchange rate exposure puzzle. Managerial Finance 33, 642-666.

Bartram, S. M., Karolyi, G. A., October 2006. The impact of the introduction of the Euro on foreign exchange rate risk exposures. Journal of Empirical Finance 13 (4-5), 519-549.

Bodnar, G., Wong, M., 2003. Estimating exchange rate exposures: issues in model structure. Financial Management 32, 35-67. 
Boudoukh, J., Richardson, M., 1993. Stock returns and inflation: A longhorizon perspective. The American Economic Review 83 (5), pp. 1346-1355.

Chen, N.-F., Roll, R., Ross, S. A., 1986. Economic forces and the stock market. The Journal of Business 59 (3), 383-403.

Choi, J. J., Jiang, C., 2009. Does multinationality matter? Implications of operational hedging for the exchange risk exposure. Journal of Banking and Finance 33 (11), 1973 - 1982.

Choi, J. J., Prasad, A. M., 1995. Exchange risk sensitivity and its determinants: A firm and industry analysis of U.S. multinationals. Financial Management $24(3), 77-88$.

Davies, D., Eckberg, C., Marshall, A., 2006. The determinants of Norwegian exporters' foreign exchange risk management. The European Journal of Finance $12(3), 217-240$.

Dimson, E., Marsh, P., Staunton, M., 2002. Triumph of the Optimists:101 Years of Global Investment Returns. Princeton University Press.

Doukas, J. A., Hall, P. H., Lang, L. H. P., 2003. Exchange rate exposure at the firm and industry level. Financial Markets, Institutions \& Instruments 12 (5), 291-346.

Dungey, M., Fry, R., González-Hermosillo, B., Martin, V. L., Tang, C., 2009. Are financial crises alike? IMF Working Paper WP/10/14, 1-58.

Fama, E. F., 1981. Stock returns, real activity, inflation, and money. The American Economic Review 71 (4), 545-565.

Fama, E. F., French, K. R., 1992. The cross-section of expected stock returns. The Journal of Finance 47 (2), 427-465.

Fama, E. F., French, K. R., 1993. Common risk factors in the returns on stocks and bonds. Journal of Financial Economics 33 (1), 3-56.

Fama, E. F., Gibbons, M. R., 1984. A comparison of inflation forecasts. Journal of Monetary Economics 13 (3), 327 - 348.

Fry, R., Martin, V., Tang, C., 2010. A new class of tests of contagion with applications. Journal of Business and Economic Statistics 28, 423-437.

Fry, R., Yu-Ling, H. C., Tang, C., 2011. Actually this time is different. CAMA Working Paper Series 12, 1-37.

Gao, T., 2000. Exchange rate movements and the profitability of U.S. multinationals. Journal of International Money and Finance 19 (1), 117-134. 
Gultekin, N. B., 1983. Stock market returns and inflation: evidence from other countries. The Journal of Finance 38 (1), pp. 49-65.

Hamao, Y., 1988. An empirical examination of the arbitrage pricing theory using Japanese data. Japan and the World Economy 1 (1), 45-61.

He, J., Ng, L., Wu, X., 1996. Foreign exchange rate exposure, risk and the Japanese stock market. Tech. rep., University of Wisconsin.

Hutson, E., O'Driscoll, A., 2010. Firm-level exchange rate exposure in the Eurozone. International Business Review 19 (5), 468 - 478.

Inci, A. C., Lee, B. S., 2011. Dynamic relations between stock returns and exchange rate changes. European Financial Management, 1-36.

Jarque, C. M., Bera, A. K., 1987. A test for normality of observations and regression residuals. International Statistical Review / Revue Internationale de Statistique 55 (2), pp. 163-172.

Jongen, R., Muller, A., Verschoor, W., 2012. Using survey data to resolve the exchange risk exposure puzzle: Evidence from U.S. multinational firms. Journal of International Money and Finance 31 (2), 148 - 169.

Jorion, P., 1990. The exchange-rate exposure of U.S. multinationals. The Journal of Business 63 (3), 331-345.

Kiymaz, H., 2003. Estimation of foreign exchange exposure: an emerging market application. Journal of Multinational Financial Management 13 (1), 7184 .

Koenker, R., Hallock, K. F., 2001. Quantile regression. The Journal of Economic Perspectives 15 (4), pp. 143-156.

Koutmos, G., Knif, J., 2011. Exchange rate exposure in the pre- and post-Euro periods: evidence from Finland. The European Journal of Finance 17 (8), $661-674$.

Meese, R. A., Rogoff, K., 1983. Empirical exchange rate models of the seventies: do they fit out of sample? Journal of International Economics 14 (1-2), 3 24 .

Miller, K. D., Reuer, J. J., 1998. Firm strategy and economic exposure to foreign exchange rate movements. Journal of International Business Studies 29 (3), pp. 493-513.

Muller, A., Verschoor, W. F., 2006a. Foreign exchange risk exposure: survey and suggestions. Journal of Multinational Financial Management 16 (4), 385 -410 . 
Muller, A., Verschoor, W. F. C., 2006b. European foreign exchange risk exposure. European Financial Management 12 (2), 195-220.

Nguyen, H., Faff, R., Marshall, A., 2007. Exchange rate exposure, foreign currency derivatives and the introduction of the Euro: French evidence. International Review of Economics and Finance 16 (4), 563 - 577.

Priestley, R., Ødegaard, B. A., 2007. Linear and nonlinear exchange rate exposure. Journal of International Money and Finance 26 (6), 1016-1037. 
Table 1: List of control variables. In accordance with Chen et al. (1986) and Doukas et al. (2003) we rely on six control variables to express the macroeconomic factors of interest: unexpected inflation, $U I$, industrial production, $I P$, term premium, $T P$, money supply, $M S$, interest rate spread, IRS, and trade balance, $T M$.

\begin{tabular}{llll}
\hline Coefficient & Variable & Symbol & Description and calculation \\
\hline$\beta_{1}$ & $C V_{1, t-1}$ & $U I_{t-1}$ & Unexpected inflation \\
& & & $\triangle \% H C P I$ \\
$\beta_{2}$ & $C V_{2, t-1}$ & $I P_{t-1}$ & Industrial production \\
& & & $\triangle \% I P$ \\
$\beta_{3}$ & $C V_{3, t-1}$ & $T P_{t-1}$ & Term premium \\
& & & $10 \mathrm{Y}$ Gov bond yield - 3M Gov bond yield \\
$\beta_{4}$ & $C V_{4, t-1}$ & $M S_{t-1}$ & Money supply \\
& & & $\triangle \% M 1$ \\
$\beta_{5}$ & $C V_{5, t-1}$ & $I R S_{t-1}$ & Interest rate spread \\
& & & $3 \mathrm{M}$ Gov bond yield differential (Foreign country; Eurozone) \\
$\beta_{6}$ & $C V_{6, t-1}$ & $X M_{t-1}$ & Trade balance \\
& & & LN(Export) - LN(Import)
\end{tabular}


Table 2: Non-Eurozone revenues on total revenues ratio (2005-2010). We compute the ratio of non-Eurozone revenues on total revenues for constituents of Euro Stoxx TMI and Euro Stoxx 50 indices by proportioning annual revenues for each period where the data are available. For the five year period from 2005 to 2010, we report the average ratio and the standard deviation of the average ratio across firms (sample standard deviation). The variability of the ratio during that period is measured for each firm and the average standard deviation of the ratio across firms is reported (time standard deviation).

\begin{tabular}{lcc}
\hline FEE index summary & Euro Stoxx TMI & Euro Stoxx 50 \\
\cline { 2 - 3 } Average & $39.52 \%$ & All firms \\
Sample standard deviation & $31.06 \%$ & $46.00 \%$ \\
Time standard deviation & $4.89 \%$ & $23.25 \%$ \\
No. firms & 567 & $4.58 \%$ \\
\hline & \multicolumn{2}{c}{ Low Exporters ${ }^{(a)}$} \\
\cline { 2 - 3 } Average & $9.42 \%$ & $12.32 \%$ \\
Sample standard deviation & $6.23 \%$ & $5.86 \%$ \\
Time standard deviation & $2.99 \%$ & $3.37 \%$ \\
No. firms & 94 & 6 \\
\hline & \multicolumn{2}{c}{ High Exporters } \\
Average & $55.33 \%$ & $51.46 \%$ \\
Sample standard deviation & $24.30 \%$ & $20.22 \%$ \\
Time standard deviation & $6.40 \%$ & $4.78 \%$ \\
No. firms & 389 & 37 \\
\hline$(a)$ We have identified 84 firms in the Euro Stoxx TMI constituent list that \\
have zero or no record of export activity. Using the same parameter as \\
in Doukas et al. (2003), we classify high exporters as firms with FEE $\geq$ \\
20\%, low exporters with 0 $<$ FEE $<20 \%$, and domestic firms are the \\
ones with FEE = 0.
\end{tabular}


Table 3: Results of the first stage regression (unexpected exchange rate returns). Model $r_{s t}=\beta_{0}+\sum_{j=1}^{6} \beta_{j} C V_{j, t-1}+\beta_{7} r_{s t-1}+\varepsilon_{s t}$ is estimated for monthly data from 1999 to 2011. The exchange rate return, $r_{s t}$, for the Euro against the JPY, USD and GBP is regressed on the set of lagged macroeconomic control variables, $C V_{j t-1}$, the first lag of the dependent variable, $r_{s t-1}$. The coefficients estimates are provided along with their associated level of significance. Normality test on the residuals from the regression is reported (JB test).

\begin{tabular}{lcccc}
\hline Variables & & JPY & USD & GBP \\
\hline Intercept & & 0.02 & 0.02 & 0.00 \\
Unexpected inflation & $U I_{t-1}$ & -3.72 & -4.38 & 2.88 \\
Industrial production & $I P_{t-1}$ & 0.14 & 0.15 & -0.11 \\
Term premium & $T P_{t-1}$ & -0.81 & -0.24 & -0.22 \\
Money supply & $M S_{t-1}$ & -0.28 & $-0.57 * *$ & 0.10 \\
Interest rate spread & $I R S_{t-1}$ & 0.28 & -0.18 & -0.18 \\
Trade balance & $X M_{t-1}$ & 0.09 & 0.05 & -0.02 \\
Lagged exchange rate return & $r_{s t-1}$ & $0.25^{* * *}$ & $0.25^{* * *}$ & 0.11 \\
\hline F statistic & & $2.73^{* *}$ & $3.25^{* *}$ & 1.67 \\
$R^{2}$ adjusted & & 0.07 & 0.09 & 0.03 \\
JB test & & $12.55^{* * *}$ & $59.31^{* * *}$ & $24.46^{* * *}$ \\
\hline
\end{tabular}

$*, * *, * * *$ denote significance at $10 \%, 5 \%$ and $1 \%$ respectively. 
Table 4: Results of the second stage regression (unexpected stock market returns). Model $r_{m t}^{M}=\beta_{0}+\sum_{j=1}^{6} \beta_{j} C V_{j, t-1}+\beta_{7} r_{m t-1}^{M}+\beta_{8} \widehat{\varepsilon_{s t}}+e_{m t}^{M}$ is estimated for monthly data from 1999 to 2011. The stock market portfolio return, $r_{m t}^{M}$, is regressed on the set of lagged macroeconomic control variables, $C V_{j t-1}$, the first lag of the dependent variable, $r_{m t-1}^{M}$ and the estimated unexpected exchange rate return, $\widehat{\varepsilon_{s t}}$. The Euro against the JPY the USD and the GBP are considered. The coefficient estimates are provided along with their associated level of significance. Normality test on the residuals from the regression is reported (JB test).

\begin{tabular}{|c|c|c|c|c|c|c|c|}
\hline \multirow{2}{*}{ Variables } & & \multicolumn{3}{|c|}{ Euro Stoxx TMI } & \multicolumn{3}{|c|}{ Euro Stoxx 50} \\
\hline & & JPY & USD & GBP & JPY & USD & GBP \\
\hline Intercept & & $0.07 * *$ & 0.02 & 0.02 & $0.06 *$ & 0.01 & 0.01 \\
\hline Unexpected inflation & $U I_{t-1}$ & $-21.60 * *$ & -14.72 & $-24.32^{* * *}$ & $-22.64 * *$ & -13.60 & - \\
\hline Industrial production & $I P_{t-1}$ & 0.13 & -0.09 & -0.01 & 0.24 & -0.01 & 0.09 \\
\hline Term premium & $T P_{t-1}$ & -0.76 & 0.66 & 0.65 & -0.46 & 0.70 & 0.68 \\
\hline Money supply & $M S_{t-1}$ & -0.17 & -0.32 & -0.46 & -0.17 & -0.36 & -0.52 \\
\hline Interest rate spread & $I R S_{t-1}$ & 0.78 & $0.81^{* *}$ & $1.46^{* * *}$ & 0.47 & $0.95^{* *}$ & $1.67 * * *$ \\
\hline Trade balance & $X M_{t-1}$ & 0.00 & 0.06 & -0.12 & -0.03 & 0.06 & -0.15 \\
\hline Lagged market return & $r_{m t-1}^{M}$ & 0.06 & 0.03 & 0.03 & 0.04 & -0.01 & -0.01 \\
\hline $\begin{array}{l}\text { Unexpected exchange } \\
\text { rate }\end{array}$ & $\varepsilon_{s t}$ & $0.43 * * *$ & 0.21 & 0.27 & $0.44^{* *}$ & 0.23 & 0.28 \\
\hline F statistic & & $2.88^{* * *}$ & $2.49 * *$ & $3.16^{* * *}$ & $2.49^{* *}$ & $2.45^{* * *}$ & $3.23^{* * *}$ \\
\hline$R^{2}$ adjusted & & 0.09 & 0.07 & 0.10 & 0.07 & 0.07 & 0.11 \\
\hline JB test & & $27.39^{* * *}$ & $33.62^{* * *}$ & $35.47^{* * *}$ & $27.37^{* * *}$ & $31.79^{* * *}$ & $29.39^{* * *}$ \\
\hline
\end{tabular}

$*, * *, * * *$ denote significance at $10 \%, 5 \%$ and $1 \%$ respectively. 


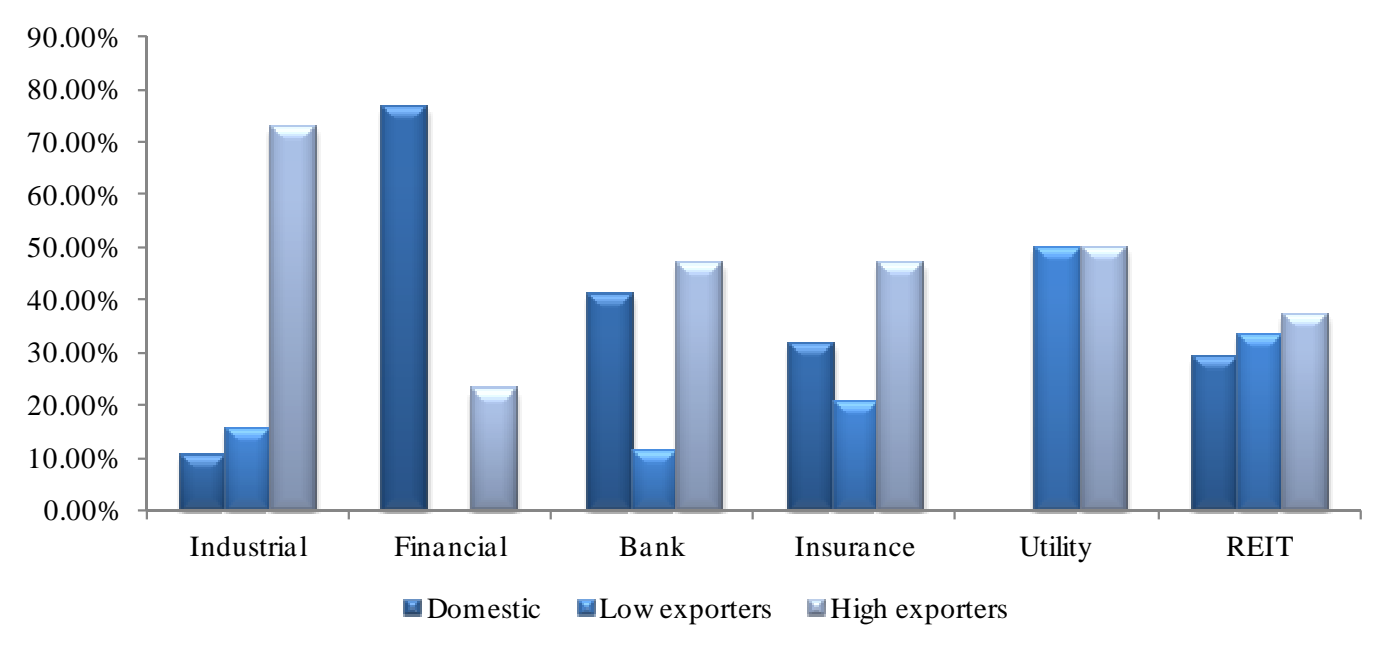

Figure 1: FEE index industry breakdown. The figure illustrates the industry breakdown of Euro Stoxx TMI constituents grouped as domestic, low exporters and MNCs. The highest concentration of MNCs (high exporters) is in the industrial sector $(73.06 \%)$ followed by the Utility $(50.00 \%)$ and the Real Estate $(37.50 \%)$. On the other side of the spectrum, the proportion of domestic firms is highly concentrated in non-industrials, that is Financials, Banking, and Insurance sectors. 


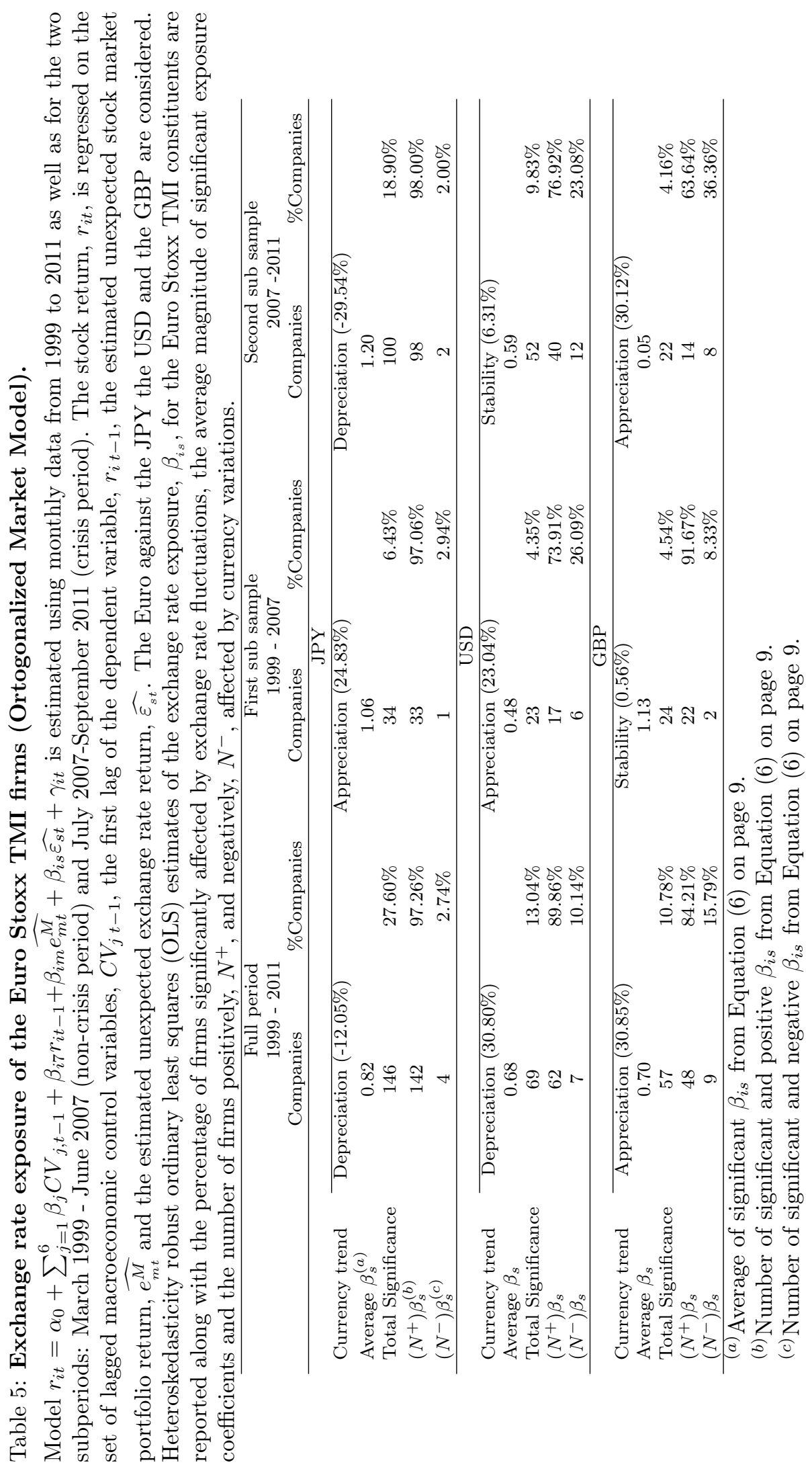




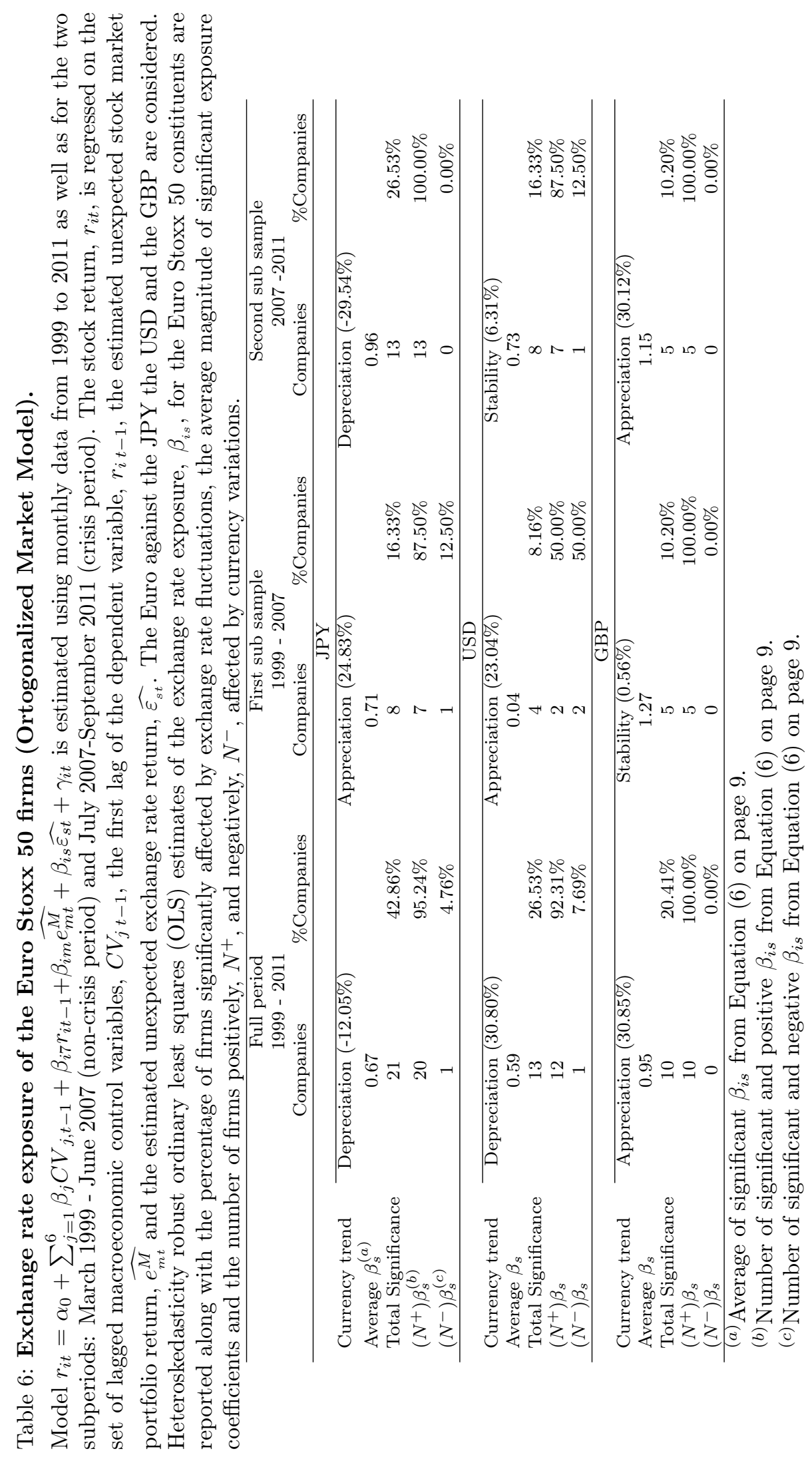




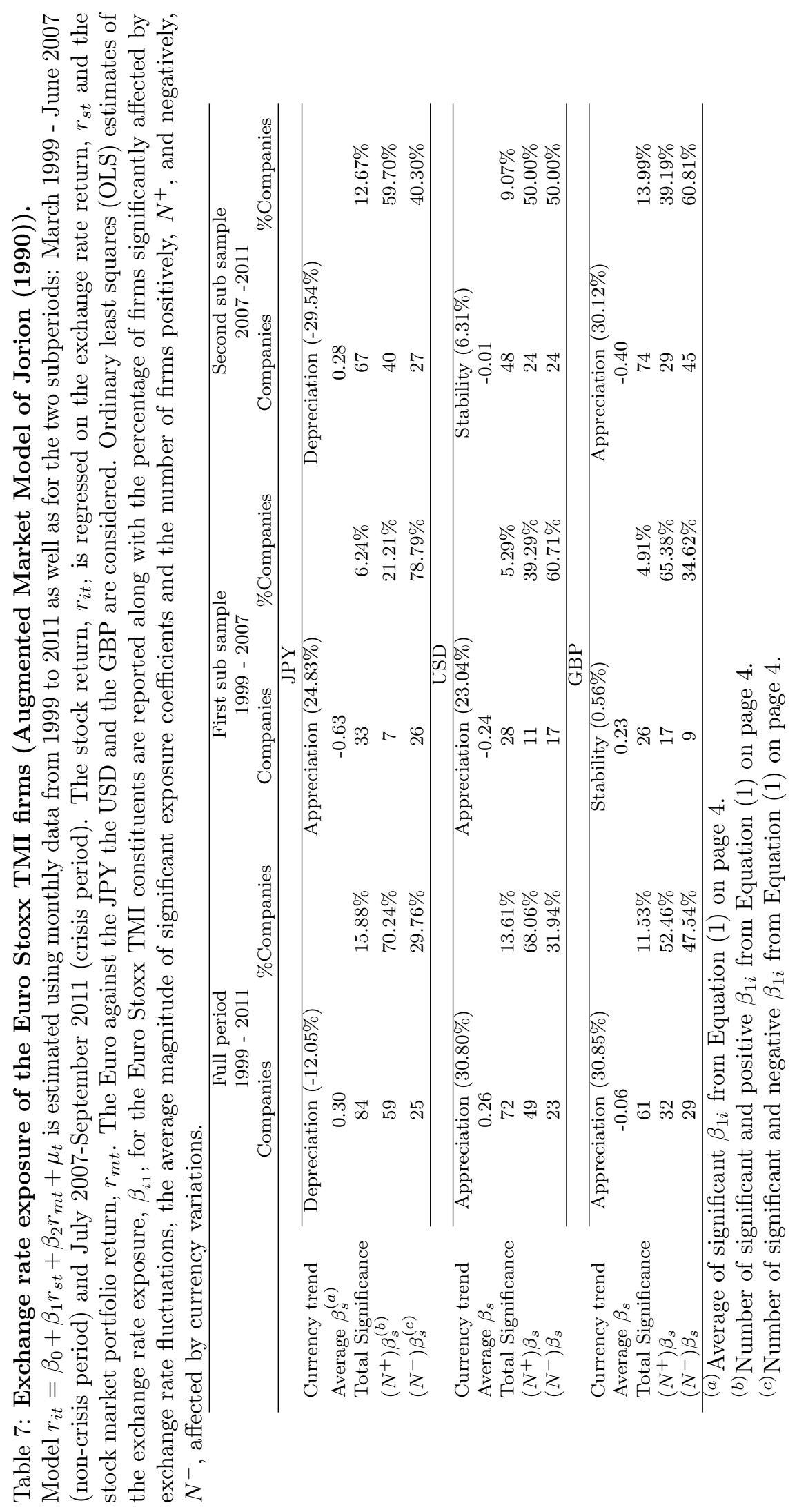




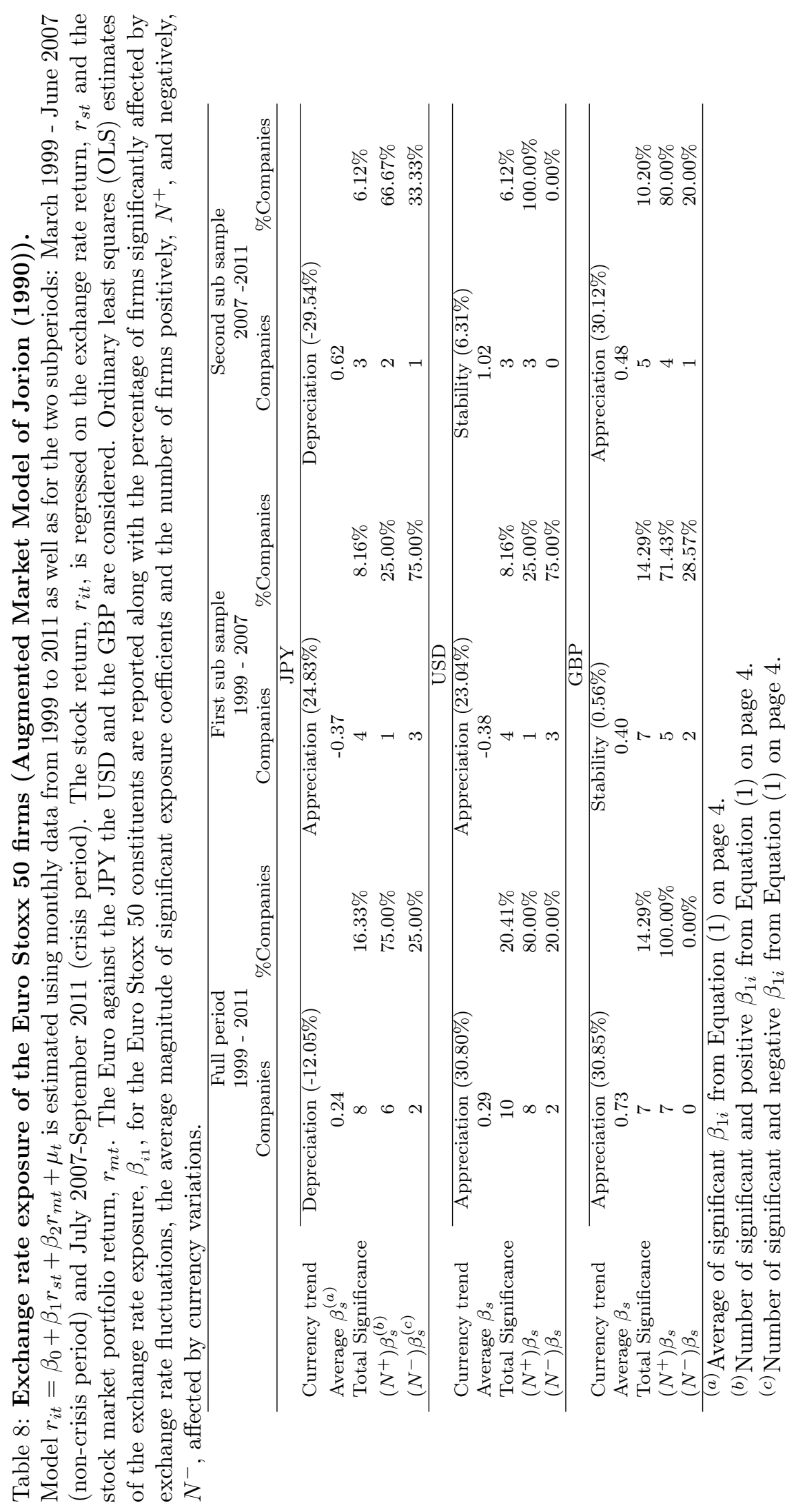




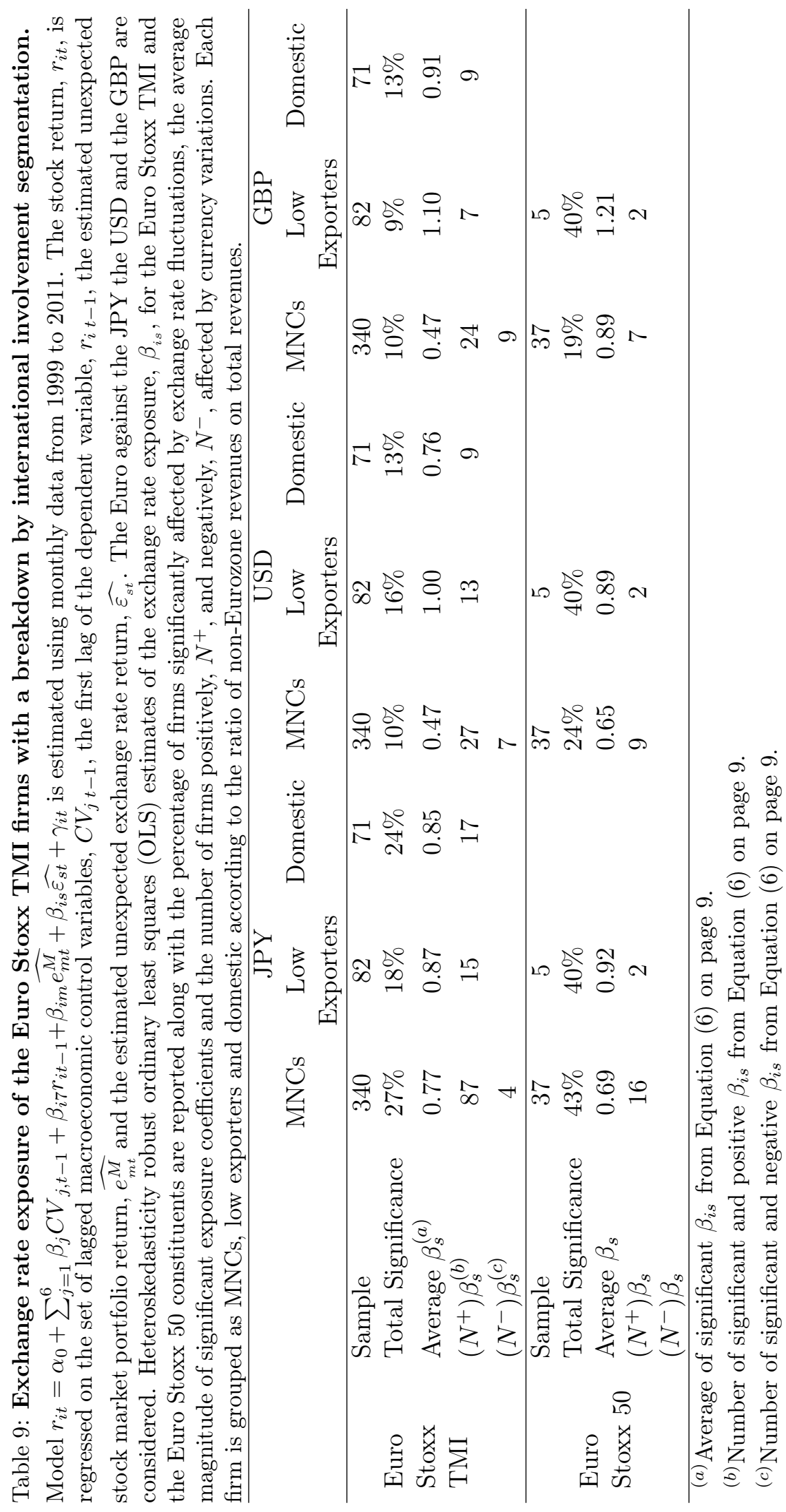




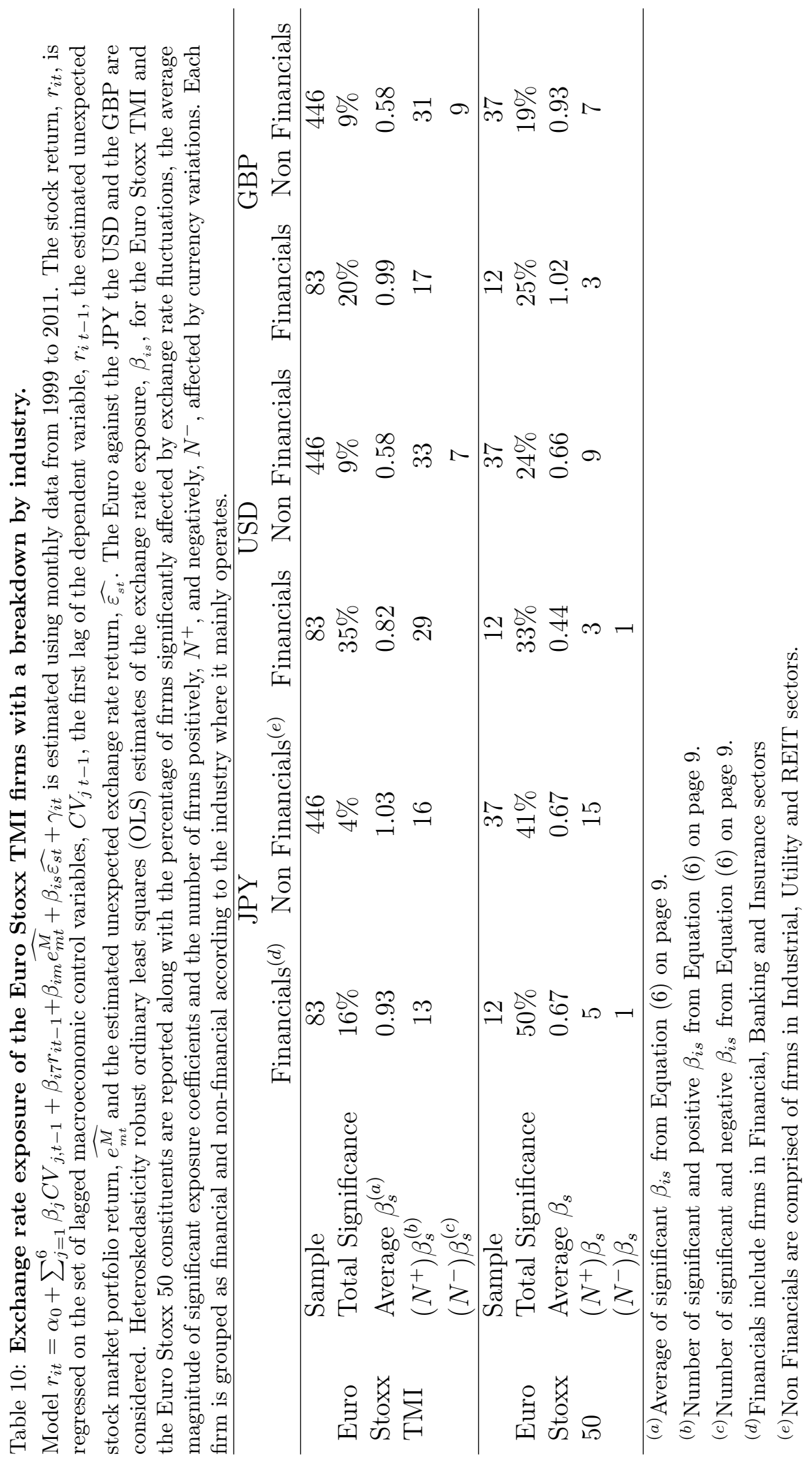




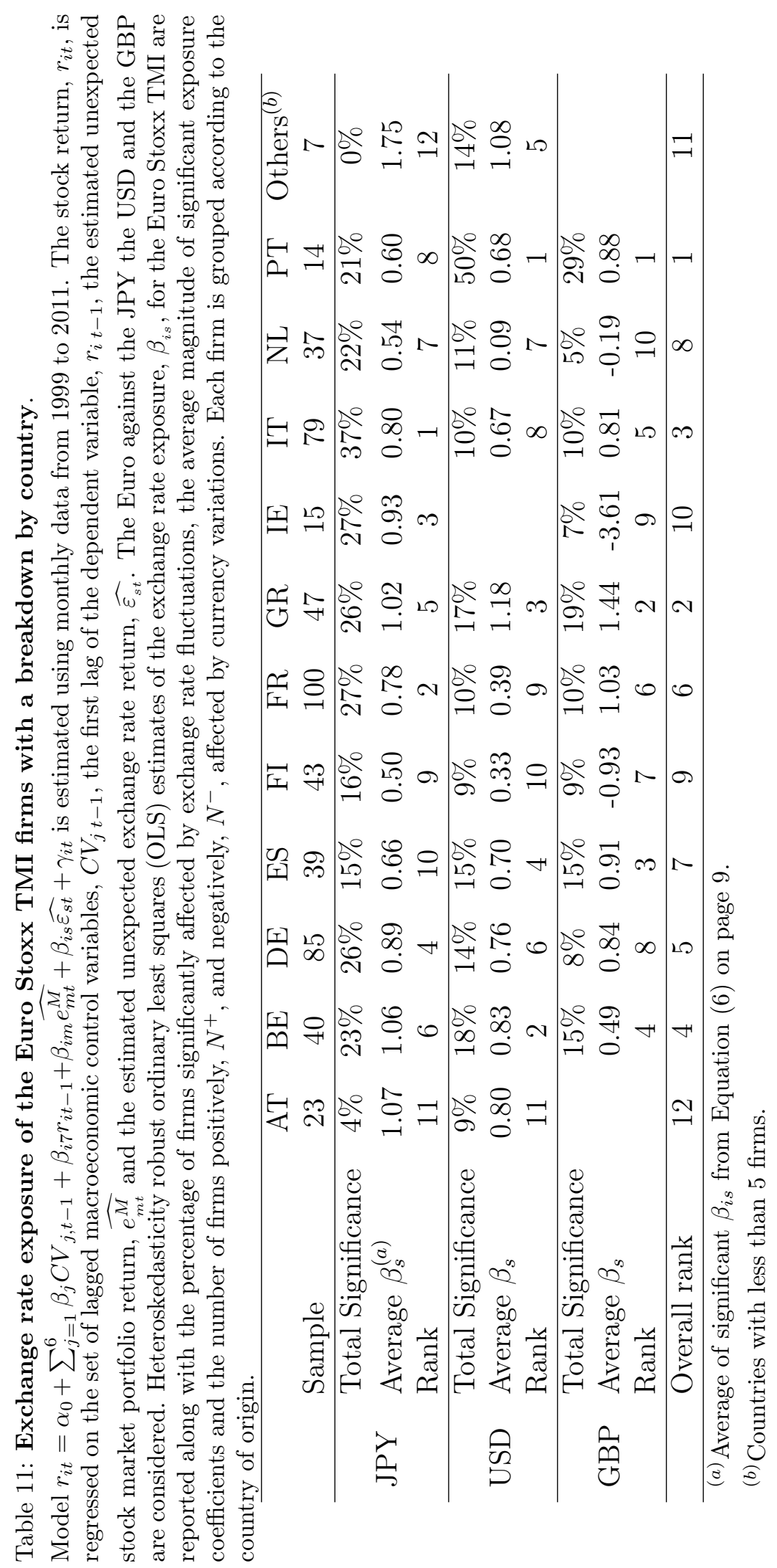




\section{JPY}
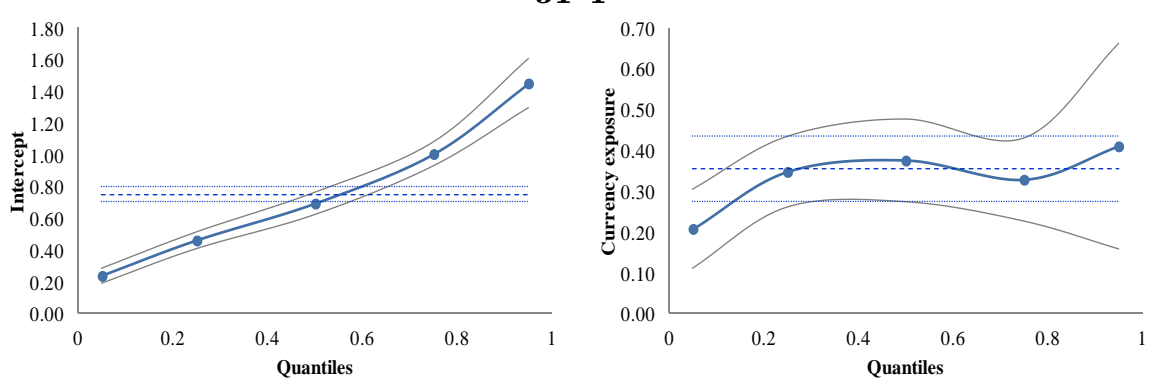

USD
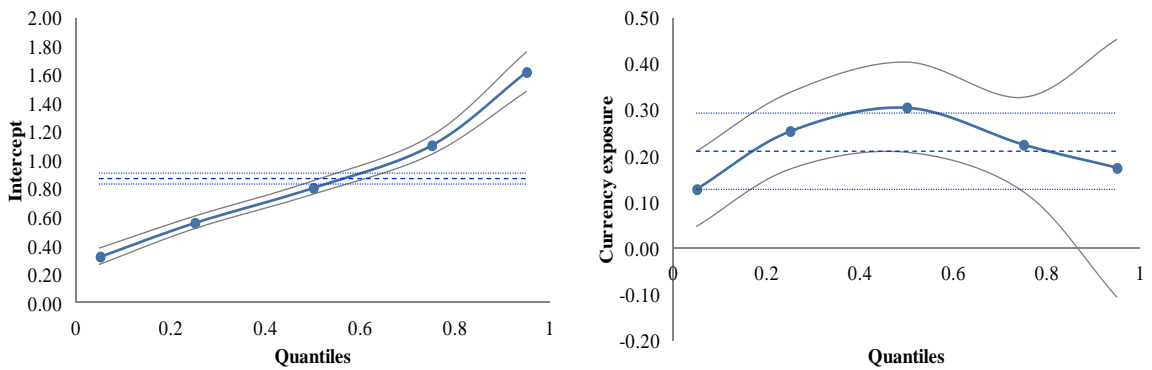

GBP
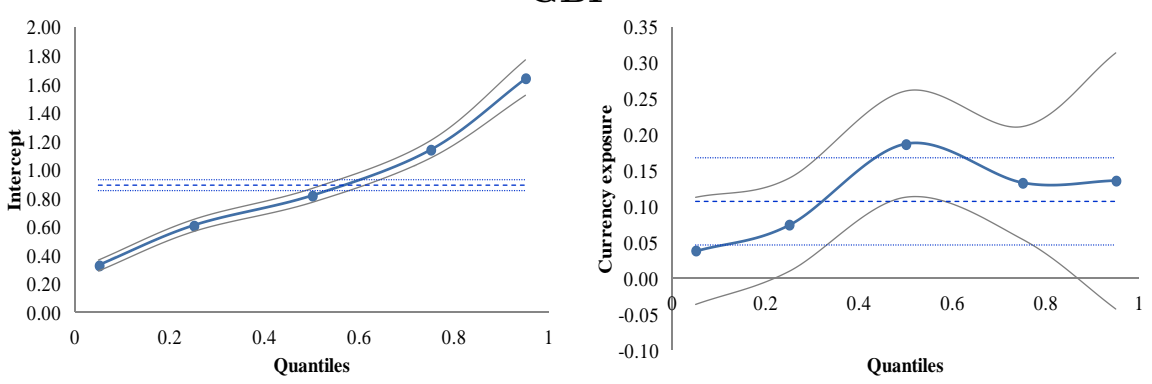

Figure 2: Relationship between exchange rate exposure and the Eurozone stock market exposure. Using quantile regression we investigate the interdependence between estimated currency betas, $\widehat{\beta_{i s}}$, and market betas, $\widehat{\beta_{i m}}$, using a quantile regression model, where the exposure to market risk, as captured by the market beta, is the response variable as in equation (7). We plot OLS quantile regression estimated for $\tau$ ranging from 0.05 to 0.95 (the solid dotted curve). For each of the plots the $x$ axis has the quantile scale and the $y$ axis as the response variable scale. In particular, each point measure the impact of a one-unit change of the currency beta on the market beta, holding other covariate fixed. The two solid curves represent $95 \%$ confidence intervals of the estimated coefficients using quantile regression. The dashed line in each plot shows OLS estimate of the conditional mean effect and the two dashed dotted lines represent conventional $95 \%$ confidence intervals for the least squares estimates. 


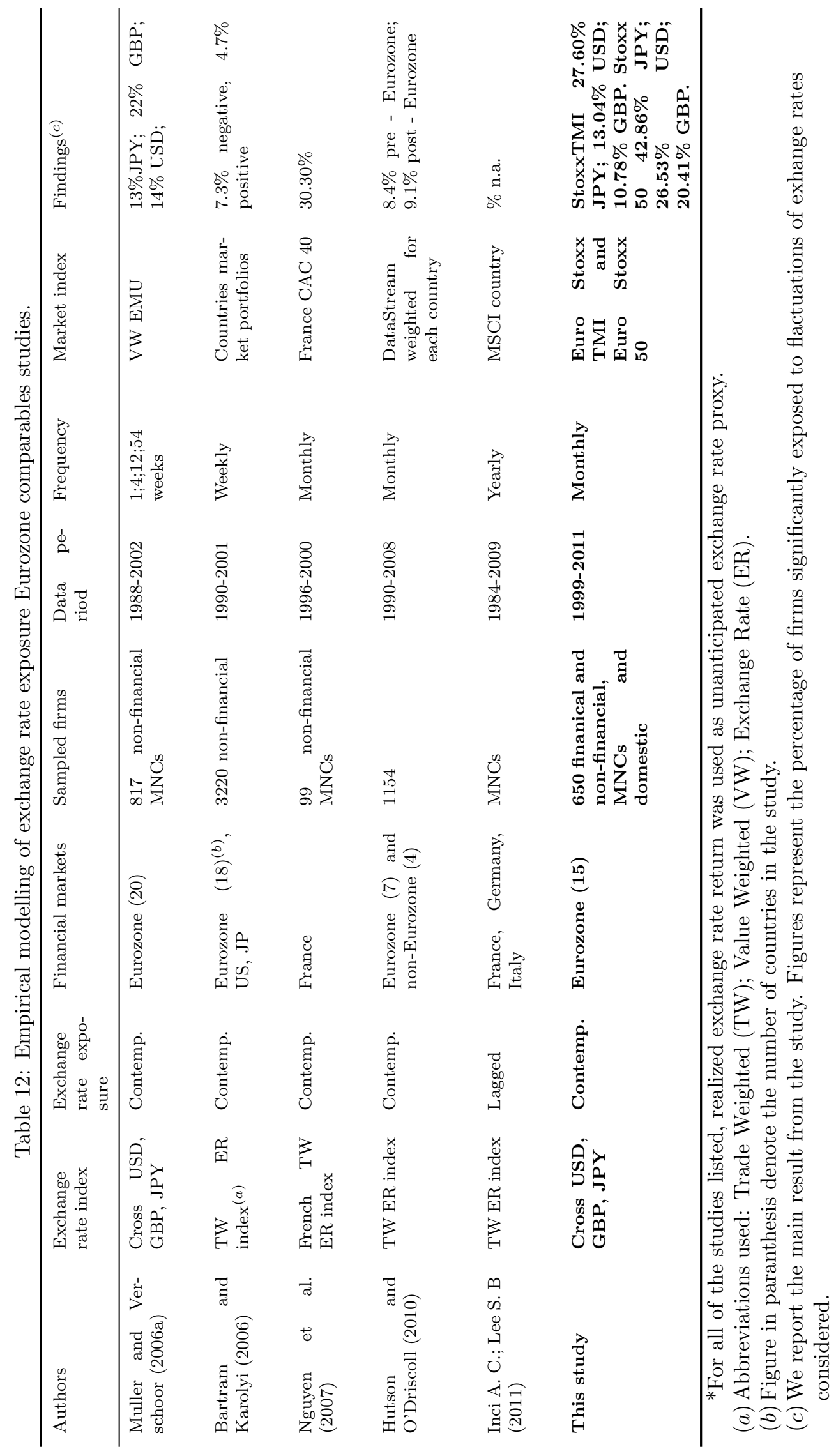


Table 13: Quantile regression: currency and market exposure betas.Quantile regression $\widehat{\beta_{i m}^{M}}=\theta_{0}+\theta_{1}\left(\widehat{\beta_{i s}}\right)+\mu_{i}$ is estimated for Euro Stoxx TMI constituents. The estimated firm's $i$ stock market risk exposure, $\widehat{\beta_{i m}^{M}}$, is regressed on the estimated exchange rate risk exposure, $\widehat{\beta_{i s}}$. The coefficients estimates are provided from the first to the fifth quantile along with the associated level of significance and the standard error (in parenthesis). These estimates are compared with OLS estimates.

\begin{tabular}{|c|c|c|c|c|c|c|}
\hline & \multicolumn{6}{|c|}{ JPY } \\
\hline & OLS & $Q_{\tau 0,05}$ & $Q_{\tau 0,25}$ & $Q_{\tau 0,50}$ & $Q_{\tau 0,75}$ & $Q_{\tau 0,95}$ \\
\hline \multirow[t]{2}{*}{$\theta_{0}$} & $0,75^{* * *}$ & $0.239^{* * *}$ & $0.462^{* * *}$ & $0.695^{* * *}$ & $1.007^{* * *}$ & $1.451^{* * *}$ \\
\hline & $(0,02)$ & -0.022 & -0.025 & -0.034 & -0.037 & -0.078 \\
\hline \multirow[t]{4}{*}{$\theta_{1}$} & $0,35 * * *$ & $0.207^{* * *}$ & $0.347^{* * *}$ & $0.375 * * *$ & $0.328 * * *$ & 0.4 \\
\hline & $(0,04)$ & -0.049 & -0.044 & -0.052 & -0.052 & -0.128 \\
\hline & \multicolumn{6}{|c|}{ USD } \\
\hline & OLS & $Q_{\tau 0,05}$ & $Q_{\tau 0,25}$ & $Q_{\tau 0,50}$ & $Q_{\tau 0,75}$ & $Q_{\tau 0,95}$ \\
\hline \multirow[t]{2}{*}{$\theta_{0}$} & $0,87 * * *$ & $0.326^{* * *}$ & $0.562^{* * *}$ & $0.807^{* * *}$ & $1.105^{* * *}$ & $1.618^{* * *}$ \\
\hline & $(0,02)$ & -0.029 & -0.022 & -0.023 & -0.033 & -0.069 \\
\hline \multirow[t]{4}{*}{$\theta_{1}$} & $0,21^{* * *}$ & $0.128^{* * *}$ & $0.253^{* * *}$ & $0.305^{* * *}$ & $0.224^{* * *}$ & 0.173 \\
\hline & $(0,04)$ & -0.041 & -0.042 & -0.05 & -0.052 & -0.142 \\
\hline & \multicolumn{6}{|c|}{ GBP } \\
\hline & OLS & $Q_{\tau 0,05}$ & $Q_{\tau 0,25}$ & $Q_{\tau 0,50}$ & $Q_{\tau 0,75}$ & $Q_{\tau 0,95}$ \\
\hline \multirow[t]{2}{*}{$\theta_{0}$} & $0,89 * * *$ & $0.329^{* * *}$ & $0.608^{* * *}$ & $0.818^{* * *}$ & $1.140^{* * *}$ & $1.640^{* * *}$ \\
\hline & $(0,02)$ & -0.019 & -0.021 & -0.025 & -0.031 & -0.063 \\
\hline \multirow[t]{2}{*}{$\theta_{1}$} & $0,11^{* * *}$ & 0.038 & $0.074^{* *}$ & $0.186^{* * *}$ & $0.132^{* * *}$ & 0.135 \\
\hline & $(0,03)$ & -0.037 & -0.033 & -0.037 & -0.04 & 0.09 \\
\hline
\end{tabular}

$*, * *, * * *$ denote significance at $10 \%, 5 \%$ and $1 \%$ respectively. 


\section{School of Economics and Finance Discussion Papers}

2012-09

2012-08

2012-07

2012-06

2012-05

2012-04

2012-03

2012-02

2012-01

2011-06

2011-05

2011-04

2011-03

2011-02

2011-01

2010-12

2010-11

2010-10

2010-09

2010-08

2010-07

2010-06

2010-05

2010-04

2010-03

2010-02

2010-01

Exchange Rate Risk Exposure and the Value of European Firms, Fabio Parlapianoa and Vitali Alexeev

Ranking Systemically Important Financial Institutions, Mardi Dungey, Matteo Luciani and David Veredas

Identification-Robust Inference for Endogeneity Parameters in Linear Structural Models, Firmin Doko Tchatoka and Jean-Marie Dufour

Specification Tests with Weak and Invalid Instruments, Firmin Doko Tchatoka

Liquidity and Crude Oil Prices: China’s Influence Over 1996-2011, Ronald A. Rattia and Joaquin L. Vespignani

On the Validity of Durbin-Wu-Hausman Tests for Assessing Partial Exogeneity Hypotheses with Possibly Weak Instruments, Firmin Doko Tchatoka

Endogenous Crisis Dating and Contagion Using Smooth Transition Structural GARCH, Mardi Dungey, George Milunovich, Susan Thorp and Minxian Yang

Testing for Partial Exogeneity with Weak Identification, Firmin Doko Tchatoka

On the Correspondence Between Data Revision and Trend-Cycle Decomposition, Mardi Dungey, Jan PAM Jacobs and Jian Tian

Systematic and Liquidity Risk in Subprime-Mortgage Backed Securities, Mardi Dungey, Gerald P. Dwyer and Thomas Flavin

A SVECM Model of the UK Economy and The Term Premium, Mardi Dungey and M. Tugrul Vehbi

Do Contact Matter in the Process of Getting a Job in Cameroon? Firmin Doko Tchatoka and Urbain Thierry Yogo

Subset Hypotheses Testing and Instrument Exclusion in the Linear IV Regression, Firmin Doko Tchatoka

First home Buyers’ Support Schemes in Australia - Results Spreadsheet, Mardi Dungey, Graeme Wells and Sam Thompson

First home Buyers’ Support Schemes in Australia, Mardi Dungey, Graeme Wells and Sam Thompson

Financial Crises in Asia: Concordance by Asset Market or Country?, Mardi Dungey, Jan P.A.M. Jacobs and Lestano

Innovation Contracts with Leakage Through Licensing, Shane B. Evans

Franchise Contracts with Ex Post Limited Liability, Shane B. Evans

Menus of Linear Contracts in Procurement with Type-Dependent Reservation Utility, Shane B. Evans

Decomposing the Price Effects on the Cost of Living for Australian Households, Paul Blacklow

Modelling the Time Between Trades in the After-Hours Electronic Equity Futures Market, Mardi Dungey, Nagaratnam Jeyasreedharan and Tuo Li

Cojumping: Evidence from the US Treasury Bond and Futures Markets, Mardi Dungey and Lyudmyla Hvozdyk

Assessing the Impact of Worker Compensation Premiums on Employment in Tasmania, Paul Blacklow

Non-Linear Pricing with Homogeneous Customers and Limited Unbundling, Hugh Sibly

Detecting Contagion with Correlation: Volatility and Timing Matter, Mardi Dungey and Abdullah Yalama

Copies of the above mentioned papers and a list of previous years’ papers are available from our home site at http://www.utas.edu.au/economics-finance/research/ 